\title{
Contributions of advection and melting processes to the decline in sea ice in the Pacific sector of the Arctic Ocean
}

\author{
Haibo Bi ${ }^{1,2,3,4}$, Qinghua Yang ${ }^{5,6,7}$, Xi Liang ${ }^{8}$, Liang Zhang ${ }^{1,2,3,4}$, Yunhe Wang ${ }^{1,2,3,4}$, Yu Liang ${ }^{1,2,3,4}$, and \\ Haijun Huang $1,2,3,4$ \\ ${ }^{1}$ Key laboratory of Marine Geology and Environment, Institute of Oceanology, \\ Chinese Academy of Sciences, Qingdao, China \\ ${ }^{2}$ Laboratory for Marine Geology, Qingdao National Laboratory for Marine Science and Technology, Qingdao, China \\ ${ }^{3}$ Center for Ocean Mega-Science, Chinese Academy of Sciences, Qingdao, China \\ ${ }^{4}$ College of Earth and Planetary Science, University of Chinese Academy of Sciences, Beijing, China \\ ${ }^{5}$ Guangdong Province Key Laboratory for Climate Change and Natural Disaster Studies, \\ School of Atmospheric Sciences, Sun Yat-sen University, Zhuhai, China \\ ${ }^{6}$ State Key Laboratory of Numerical Modeling for Atmospheric Sciences and Geophysical Fluid Dynamics, \\ Institute of Atmospheric Physics (IAP), Chinese Academy of Sciences, Beijing, China \\ ${ }^{7}$ Southern Marine Science and Engineering Guangdong Laboratory (Zhuhai), Zhuhai, China \\ ${ }^{8}$ Key Laboratory of Research on Marine Hazards Forecasting, National Marine Environmental Forecasting Center, \\ Beijing, China
}

Correspondence: Haibo Bi (bhb@qdio.ac.cn)

Received: 15 January 2019 - Discussion started: 22 January 2019

Revised: 9 April 2019 - Accepted: 17 April 2019 - Published: 8 May 2019

\begin{abstract}
The Pacific sector of the Arctic Ocean (PA, hereafter) is a region sensitive to climate change. Given the alarming changes in sea ice cover during recent years, knowledge of sea ice loss with respect to ice advection and melting processes has become critical. With satellite-derived products from the National Snow and Ice Center (NSIDC), a 38-year record (1979-2016) of the loss in sea ice area in summer within the Pacific-Arctic (PA) sector due to the two processes is obtained. The average sea ice outflow from the PA to the Atlantic-Arctic (AA) Ocean during the summer season (June-September) reaches $0.173 \times 10^{6} \mathrm{~km}^{2}$, which corresponds to approximately $34 \%$ of the mean annual export (October to September). Over the investigated period, a positive trend of $0.004 \times 10^{6} \mathrm{~km}^{2} \mathrm{yr}^{-1}$ is also observed for the outflow field in summer. The mean estimate of sea ice retreat within the PA associated with summer melting is $1.66 \times 10^{6} \mathrm{~km}^{2}$, with a positive trend of $0.053 \times 10^{6} \mathrm{~km}^{2} \mathrm{yr}^{-1}$. As a result, the increasing trends of ice retreat caused by outflow and melting together contribute to a stronger decrease in sea ice coverage within the PA $\left(0.057 \times 10^{6} \mathrm{~km}^{2} \mathrm{yr}^{-1}\right)$ in summer. In percentage terms, the melting process ac-
\end{abstract}

counts for $90.4 \%$ of the sea ice retreat in the PA in summer, whereas the remaining $9.6 \%$ is explained by the outflow process, on average. Moreover, our analysis suggests that the connections are relatively strong $(R=0.63)$, moderate ( $R=-0.46)$, and weak $(R=-0.24)$ between retreat of sea ice and the winds associated with the dipole anomaly (DA), North Atlantic Oscillation (NAO), and Arctic Oscillation (AO), respectively. The DA participates by impacting both the advection $(R=0.74)$ and melting $(R=0.55)$ processes, whereas the NAO affects the melting process $(R=-0.46)$.

\section{Introduction}

As the Arctic climate warms (Comiso, 2010; Overland et al., 2010; Graham et al., 2017), a wide range of researchers and the public show compelling interest in topics associated with the drop in sea ice coverage (Kay and Gettelman, 2009; Spreen et al., 2009, 2011; Polyakov et al., 2010; Zhang et al., 2010; Woods et al., 2013; Tjernström et al., 2015; Notz and Stroeve, 2016; Screen and Francis, 2016; Koyama et al., 
2017; Smedsrud et al., 2017; Stroeve et al., 2017; Niederdrenk and Notz, 2018). For the period since the late 1970s, sea ice extent has been decreasing as revealed from a series of satellite microwave observations, ranging from -0.45 to $-0.39 \% \mathrm{yr}^{-1}$ depending on different data products (Comiso et al., 2017). Specifically, the September Arctic sea ice extent has been found to be the month with the most rapid decrease , at approximately $-1.30 \% \mathrm{yr}^{-1}$ for the period 1979-2017.

Comiso (2011) reported a more negative trend in the multiyear ice (MYI) coverage, approximately $-1.72 \% \mathrm{yr}^{-1}$ in winter over the period 1979-2011. As a result, the MYI extent decreased from approximately $6.2 \times 10^{6} \mathrm{~km}^{2}$ in the $1980 \mathrm{~s}$ to only $2.8 \times 10^{6} \mathrm{~km}^{2}$ in the late $2000 \mathrm{~s}$. Recently, record lows in sea ice extent have been frequently set in summer over the past years (Serreze et al., 2003; Parkinson and Comiso, 2013; Stroeve et al., 2013). According to the National Snow and Ice Data Center (NSIDC) report (http://nsidc.org/arcticseaicenews/2012/09/ arctic-sea-ice-extent-settles-at-record-seasonal-minimum/, last access: 7 May 2019), the Arctic sea ice extent plummeted to its minimum of $3.41 \times 10^{6} \mathrm{~km}^{2}$ on 16 September 2012, approximately $18 \%$ below the previous record minimum in 2007. The significant decline in sea ice coverage in summer implies that less Arctic sea ice can survive the melting season to replenish the MYI cover in September (Kwok, 2007). Therefore, the Arctic Ocean is now dominated by younger and thinner first-year ice (FYI) (Maslanik et al., 2011; Tschudi et al., 2016), which is usually thinner and saltier and melts at a lower temperature.

Much attention is also paid to the decline in sea ice thickness in the Arctic Ocean. The sea ice extent covered by MYI in March decreased from approximately $75 \%$ (mid-1980s) to $45 \%$ (2011), and coverage fraction of the oldest ice (no less than a fifth of a year) dropped from $50 \%$ of the multiyear ice cover to $10 \%$ (Comiso, 2011). Such a large decline in coverage of the thicker and older component of the MYI ice cover means a decrease in the mean ice thickness in the Arctic Ocean. For example, placing sea ice thickness derived from ICESat (2003-2008) in the context of a 43-year submarine record (1958-2000), the overall mean winter thickness in a sizable portion of the central Arctic Ocean shows a decline of $1.75 \mathrm{~m}$ in thickness from $3.64 \mathrm{~m}$ in 1980 to $1.75 \mathrm{~m}$ from the ICESat record (Kwok and Rothrock, 2009). Moored sonars in the Fram Strait also observed a decrease in the annual mean sea ice thickness, from earlier $3.0 \mathrm{~m}(1990 \mathrm{~s})$ to recent 2.2 m (2008-2011) (Hansen et al., 2013). Due to Arctic sea ice age changes, satellite measurements from 2003 to 2008 (ICESat) and CryoSat-2 (2011-2015) reveal that there are net reductions in Arctic ice volume, of approximately $4.68 \times 10^{3} \mathrm{~km}^{3}$ in autumn and $1.46 \times 10^{3} \mathrm{~km}^{3}$ in winter $(\mathrm{Bi}$ et al., 2018). The thinner ice pack is more dynamically responsive to the drag forcing of winds and currents, allowing the Arctic sea ice to drift at a higher speed (Rampal et al., 2009; Spreen et al., 2011; Zhang et al., 2012; Kwok et al.,
2013). Consequently, advective sea ice mass balance within the Arctic Ocean may have been changing.

Although we are familiar with the fact that the sea ice mass balance is closely related to the dynamic (advection) and thermodynamic (melting) processes, quantitative knowledge about their contributions to the sea ice area changes within the Arctic Ocean is scarce. In addition the utilization of satellite observations, modeling studies have been commonly used to diagnose the dynamic and thermodynamic forcing (e.g., Lindsay et al., 2009). In this study, we examine the contributions of these two processes to the sea ice depletion within the PA side where sea ice loss is the most pronounced during summer (Cavalieri and Parkinson, 2012; Kawaguchi et al., 2014; Lynch et al., 2016; Comiso et al., 2017). In a preceding investigation, Kwok (2008a) examined the sea ice retreat within the PA sector due to melting and advection in the summers of 2003-2007. However, the record of 5 years is too short to draw any robust conclusion about the variability and trend in the sea ice area changes due to the two processes. Kwok (2008b) investigated the sea ice transport between the PA and Atlantic-Arctic (AA) sectors for the period 1979-2007. However, the contribution of ice melting to sea ice decline in PA is beyond the scope of their study. Taking advantage of a longer and updated version of sea ice motion data provided by the NSIDC, this study attempts to quantify the contributions of the two processes (advection and melting) to the retreat of sea ice in summer within the PA sector over the period 1979-2016. Moreover, the possible causes for their variability and trends are examined by highlighting the role of large-scale atmospheric circulation.

We organize this paper as follows. The data and method are summarized in Sect. 2. The estimates of sea ice outflow and melting are presented in Sect. 3. The connection between sea ice retreat within the PA sector and typical large-scale atmospheric circulation is analyzed in Sect. 4 by exploring the connection between the PA sea ice loss and the Arctic Oscillation (AO), North Atlantic Oscillation (NAO), and dipole anomaly (DA). Section 5 reiterates the key findings and concludes this study.

\section{Data and method}

\subsection{Sea ice motion and concentration}

A gridded sea ice motion (SIM) product is provided by the National Snow and Ice Data Center (NSIDC) (http: //nsidc.org/data/NSIDC-0116, last access: 18 March 2019) (Tschudi et al., 2019a). SIM vectors are retrieved from a wide selection of platforms, from satellite radiometers, including the Advanced Very High Resolution Radiometer (AVHRR), Scanning Multichannel Microwave Radiometer (SMMR), Special Sensor Microwave Imager (SSM/I), Special Sensor Microwave Imager Sounder (SSMIS), and Advanced Microwave Scanning Radiometer-Earth observing 
system (AMSR-E), to the International Arctic Buoy Program (IABP) buoy data and surface winds from the $\mathrm{Na}$ tional Centers for Environmental Prediction and the National Center for Atmospheric Research (NCEP/NCAR). The version of the SIM product (v3.0) is available with a grid of $25 \mathrm{~km} \times 25 \mathrm{~km}$, and is mapped on an EASE-Grid projection, which is an equal-area projection (Tschudi et al., 2019a, b). The IABP buoy observations were employed throughout the product with a few unrealistic buoys being removed due to errors (Szanyi et al., 2016). Likewise, AVHRR imagery is used for the period 1979-2000 with some error sources excluded. Overall, the SIM data are estimated to have an uncertainty of between 1 and $2 \mathrm{~cm} \mathrm{~s}^{-1}$ depending on the amplitudes of both the sea ice concentration (SIC) and SIM (Sumata et al., 2015). At the time this study was conducted, daily SIM data from 1979 through 2016 were available. Note that the newest version of the SIM product (Tschudi et al., 2019b) will soon be released, based on which further analysis is expected.

Satellite-derived daily SIC records (1978-2017) (http:// nsidc.org/data/NSIDC-0079, last access: 18 March 2019) (Comiso, 2017) were also obtained from NSIDC. Common with the SIM product, SIC is also extracted from multiple passive microwave observations from SMMR, SSM/I, and SSMIS by the application of the bootstrap (BT) algorithm. Over the period November 1978 to July 1987 the ice concentration is available every other day. The data gap is filled using a temporal interpolation from the data of the two adjacent days (i.e., the previous and subsequent days). The concentration field utilized here is an up-to-date version (v3.1), offering improved consistency among the estimates from the different satellite observations through the application of varying tie points on a daily basis. Furthermore, the product is optimized to further remove the effects of weather and land contamination (Cho et al., 1996). The data are available on a polar stereographic projection.

\subsection{Procedure to estimate regional sea ice exchanges and melt}

Following Kwok (2008a), the Arctic Ocean is divided into the PA and AA sectors (Fig. 1). The division is defined by a line linking the easternmost tip of Severnaya Zemlya and the southwestern tip of Banks Island. With a length of $2840 \mathrm{~km}$, the line serves as the gateway through which the sea ice area flux between the two sides of the Arctic Ocean is calculated.

Sea ice area flux is taken as the integral product of gateperpendicular SIM and SIC for all grids across the fluxgate. The daily field of sea ice area flux $\left(F, \mathrm{~km}^{2} \mathrm{~d}^{-1}\right)$ is written as

$F=\sum_{i=1}^{N-1} u_{i} c_{i} \Delta x \quad(i=1,2, \ldots, N)$

where $u, c$, and $\Delta x$ correspond to the gate-perpendicular SIM $\left(\mathrm{km} \mathrm{d}^{-1}\right)$, SIC, and the width of a grid $(25 \mathrm{~km})$, and $i=1,2, \ldots N$ refers to the index of grid cells along the gate.

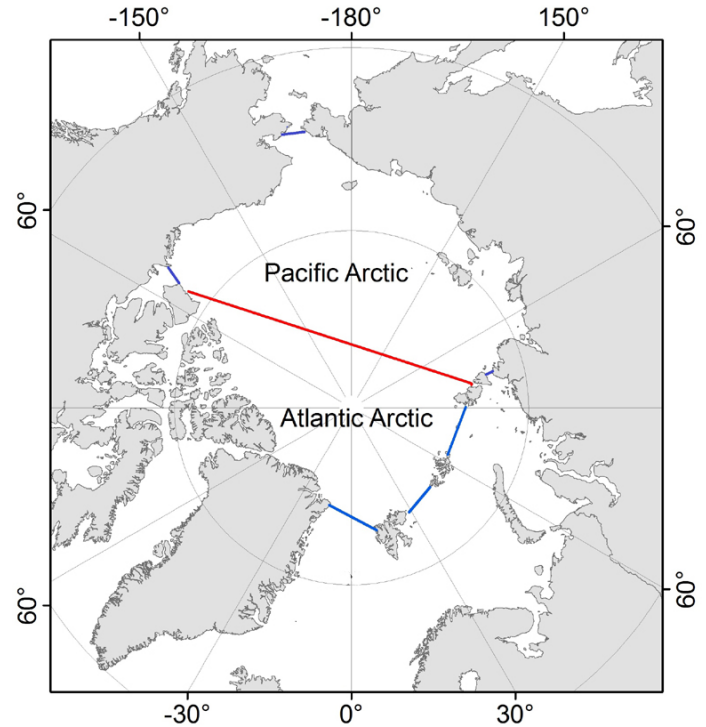

Figure 1. The fluxgate (red line) that is used to estimate sea ice area flux. The blue lines represent the boundaries of the PA and AA regimes. The endpoints in the North American and the Eurasian sides are $\left(125.1^{\circ} \mathrm{W}, 73.0^{\circ} \mathrm{N}\right)$ and $\left(101.0^{\circ} \mathrm{E}, 79.6^{\circ} \mathrm{N}\right)$, respectively.

The length $(\mathrm{km})$ of the chosen gate corresponds to the total width of 113 grids. The monthly area flux $\left(F_{\mathrm{m}}\right)$ is the sum of daily fluxes for the corresponding calendar month, and the seasonal flux denotes the accumulative fluxes over the summer (June-September) and winter (October-May) months. Likewise, the annual flux is taken as the integrated flux over annual cycles between October and September (i.e., the sum of the winter and summer estimates). Although the focus season of this study is summer, the winter and annual fluxes across the gate are also presented for comparison to help readers understand the relative contribution of summer advection to the regional sea ice balance. We should note that the data quality for the daily SIC and SIM fields is likely lower during summer due to the surface melting process.

In our sign convention, sea ice transport from the PA to the AA sector is referred to as a positive flux (i.e., outflow) and the reverse direction is taken as a negative flux (i.e., inflow). Supposing that the errors in the SIM grid samples are unbiased, additive, uncorrelated, and normally distributed (Kwok, 2008 b), the uncertainty of the daily fields can be expressed as follows.

$\sigma_{F}=\frac{\sigma_{\mathrm{d}} L}{\sqrt{N}}$

where $L$ represents the fluxgate width $(2840 \mathrm{~km})$, and $\sigma_{\mathrm{d}}$ is the uncertainty in the daily SIM. Regarding the daily drift uncertainty for one ice sample $\left(\sigma_{\mathrm{d}}\right)$, we use the uncertainty reported in Sumata et al. (2015), which is estimated by comparing NSIDC SIM data with buoy drifts and varies on the basis of the magnitudes of SIC and SIM. The uncertainty of the daily sea ice motion data during winter is obtained 
Table 1. Expected mean uncertainties in seasonal and annual sea ice area flux $\left(10^{6} \mathrm{~km}^{2}\right)$.

\begin{tabular}{lrrrr}
\hline $\begin{array}{l}\text { Length of } \\
\text { fluxgate }\end{array}$ & $N$ & $\sigma_{\text {summer }}$ & $\sigma_{\text {winter }}$ & $\sigma_{\text {annual }}$ \\
\hline $2840 \mathrm{~km}$ & 113 & 0.004 & 0.005 & 0.007 \\
\hline
\end{tabular}

as $2 \mathrm{~cm} \mathrm{~s}^{-1}$ (i.e., $1.70 \mathrm{~km} \mathrm{~d}^{-1}$ ) (Sumata et al., 2015). For the summer period, however, the ice motion is often blurred by surface melting. Therefore, summer ice motion mainly relies on interpolation that introduces additional uncertainty and thus has a poorer quality. As a result, we presumed summerperiod uncertainty to be twice the winter error, up to $4 \mathrm{~cm} \mathrm{~s}^{-1}$ (i.e., $3.40 \mathrm{~km} \mathrm{~d}^{-1}$ ) in the fluxgate. Assessment for ice concentration fields show there is a uncertainty of $3 \%$ in wintertime consolidated ice areas, whereas it is estimated to be about $5-10 \%$ in summer when melt-ponding effects play a role (Meier, 2005). In this study, we use $3 \%$ and $10 \%$ as the representative value of ice concentration uncertainties during winter and summer periods, respectively (Meier, 2005).

The uncertainty of the seasonal $\left(\sigma_{\text {summer }}\right.$ and $\left.\sigma_{\text {winter }}\right)$ or annual area flux estimates ( $\left.\sigma_{\text {annual }}\right)$ can be described as

$\sigma=\sigma_{F} \sqrt{N_{\mathrm{D}}}$

where $N_{\mathrm{D}}$ denotes the days for the period examined. Based on these equations, the expected uncertainties for the sea ice area flux estimates are obtained. The uncertainties listed in Table 1 correspond to $2.2 \%, 1.4 \%$, and $1.2 \%$ of the mean flux (as shown in Sect. 3.1.3) during summer, summer, and annual periods, respectively.

According to Kwok (2008a), the melting sea ice area in PA is the difference between the total sea ice area loss in PA and the sea ice area flux from PA to AA. A possible discrepancy is caused by deformation (divergence and convergence) processes, which can lead to reduction in sea ice area that may be misclassified as sea ice loss due to melt or export. The coarse resolution of satellite observations does not allow us to accurately quantify the sea ice loss in relation to sea ice deformation. However, in winter, sea ice area change due to deformation is expected to be negligible due to solid pack ice (approximately 1\%-2\%) (Kwok et al., 1999). In summer, the deformation may be larger. A larger (smaller) convergence (divergence) is hypothesized north (south) of $80^{\circ} \mathrm{N}$. For example, the accumulated divergence south (north) of $80^{\circ} \mathrm{N}$ is approximately 14\% (25\%) in 2007 (Kwok and Cunningham, 2012). The PA sector is an area located mostly south of $80^{\circ} \mathrm{N}$ where ice divergence is more likely to occur in summer, and new ice likely does not form within the divergence area due to warm temperature. In this study, it is difficult to quantitatively separate the ice loss due to deformation from the melting process. However, a sophisticated model study (Lindsay et al., 2009) suggests the convergence accounts for $1 \%$ of the Arctic basin ice loss in the Atlantic sector. Since the Pacific sector is dominated by divergence over the major parts (Lindsay et al., 2009), convergence may contribute to a percentage of no more than $1 \%$. This is much less than the estimated melting trend, approximately $3.2 \% \mathrm{yr}^{-1}$ for the 1979-2016 period as shown in Fig. 11. Based on these findings, we ignore the limited contributions of convergence and divergence to sea ice area balance within the PA side.

\subsection{Large-scale atmospheric circulation index}

The atmosphere circulation modes screened in this study for possible linkages with sea ice area changes in PA include the AO (leading mode of sea level pressure (SLP) north of $20^{\circ} \mathrm{N}$ ) (Thompson and Wallace, 1998), NAO (leading mode of SLP over the North Atlantic) (Hurrell, 1995), and DA (the second-leading mode of SLP within the Arctic Circle north of $70^{\circ} \mathrm{N}$ ) (Wu et al., 2005). Both the AO and NAO indices (1979-2016) are available at the following sites affiliated with the Climate Prediction Center (CPC) at the National Oceanic and Atmospheric Administration (NOAA): http://www.cpc.ncep.noaa.gov/products/ precip/CWlink/daily_ao_index/ao.shtml (last access: 6 April 2019) and http://www.cpc.ncep.noaa.gov/products/precip/ CWlink/pna/nao_index.html (last access: 6 April 2019). The DA corresponds to the second-leading mode of the empirical orthogonal function (EOF) of monthly mean sea level pressure (SLP) north of $70^{\circ} \mathrm{N}$ during the winter season (October to May; Wu et al., 2005). The SLP fields are obtained from the National Centers for Environmental Prediction (NCEP) and the National Center for Atmospheric Research (NCAR). The record of the DA index (1979-2016) was provided by Bingyi Wu at Fudan University (personal communication, 2019).

\subsection{Arctic climate variables}

The changes in SLP can have significant impacts on winds and hence SIM through their perturbations of other climate variables, such as surface air temperature (SAT) and precipitable water $(\mathrm{PW})$. All these data are obtained from NCEP/NCAR in NOAA (Kalnay et al., 1996), with a grid size of $2.5^{\circ} \times 2.5^{\circ}$.

\section{Results}

\subsection{Sea ice transport between the Pacific-Arctic and Atlantic-Arctic oceans}

\subsubsection{Comparison with a previous estimate}

To give credence to our estimates, we compared the estimates with the results reported by Kwok (2008b). He made use of the SIM data retrieved from the $37 \mathrm{GHz}$ channels of the combined 29-year SMMR and SSM/I time series between 1979 and 2007. Overall, the two estimates agree well with 

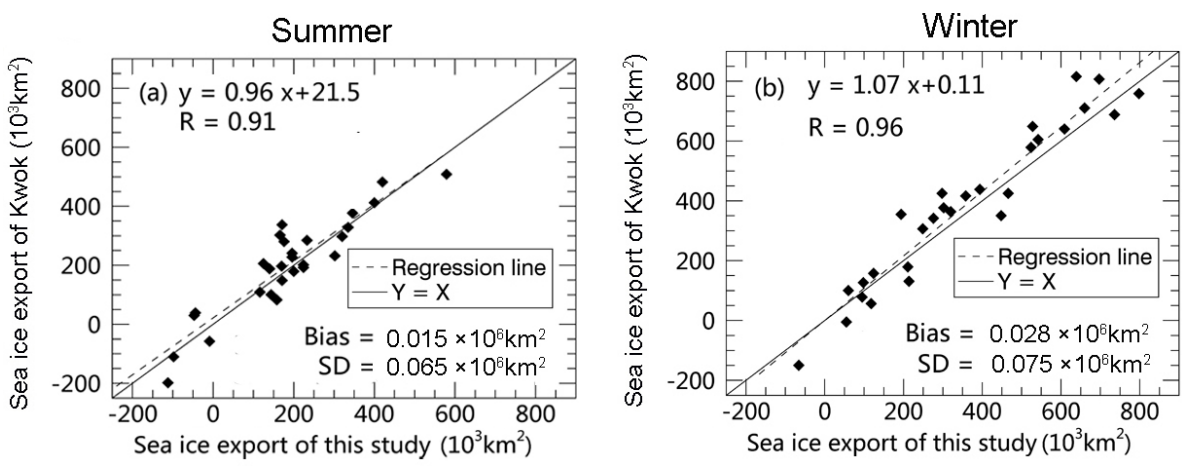

Figure 2. Comparison of regional sea ice exchanges between the PA and AA sectors in (a) summer and (b) winter. Our estimates are compared with a previous 29-year record (1979-2007) provided by Kwok (2008b). The dashed line is the linear fit line between the two estimates. The solid line denotes the " $Y=X$ " line. The linear relationship equation and correlation coefficient $(R)$ between the two records, as well as the mean bias and standard deviation (SD) of the difference, are also displayed.

respect to summer and winter sea ice area fluxes (Fig. 2). As shown in Fig. 2, data pairs are distributed close to the $Y=X$ line. There is a small mean positive bias between the two estimates, with Kwok's estimates slightly larger than ours, approximately $0.015 \times 10^{6} \mathrm{~km}^{2}$ in summer (Fig. 2a) and $0.028 \times 10^{6} \mathrm{~km}^{2}$ in winter (Fig. 2b). These biases correspond to $8.6 \%$ and $8.2 \%$ of the mean estimates of sea ice area flux (as shown below in Sect. 3.1.3) during summer $\left(0.173 \times 10^{6} \mathrm{~km}^{2}\right)$ and winter $\left(0.337 \times 10^{6} \mathrm{~km}^{2}\right)$ seasons, respectively. Moreover, a good consistency in terms of interannual variability is identified as indicated by high correlation coefficients ( $R=0.91$ in summer and $R=0.96$ in winter).

\subsubsection{Monthly sea ice area flux}

The normalized monthly anomaly data have been adopted for studying the monthly variability. As a result, the seasonal variability is removed and, therefore, the distinct variations in monthly estimates are clearer and a direct comparison of variability among different months is feasible. The normalized or standardized procedure applied for the monthly anomaly fields $\left(F_{\mathrm{a}}\right)$ can be written as

$F_{\mathrm{a}}=\frac{F_{\mathrm{m}}-F_{\mathrm{m}}^{\prime}}{\sigma_{F_{\mathrm{m}}}}$,

where $F_{\mathrm{m}}$ represents monthly area flux and $F_{\mathrm{m}}^{\prime}$ and $\sigma_{F_{\mathrm{m}}}$ indicate the means and standard deviations (SDs) of the corresponding month over the investigated period (1979-2016), respectively, and the results are shown in Fig. 3.

Figure 3 displays the variations in anomaly fields for monthly sea ice flux between the two subsectors in the Arctic Ocean. Overall, the temporal variability is high (Fig. 3). The first decade (1979-1988) is characterized by the occurrence of frequent negative anomaly fields, while for the remaining periods the emergence of positive anomalies seems to be more common (Fig. 3). In particular, negative anomalies are observed in nearly all months (except for February) in 1985, yet almost all months experience positive ice flow anomalies in 1995, 2007, and 2008. The frequently observed positive anomaly in recent periods compared to the early period (1979-1987) is further reflected in the annual mean normalized anomaly (bottom row in Fig. 3).

The temporal variability in the monthly sea ice area flux fields is further emphasized in Fig. 4, where the frequency distribution histogram for months with different normalized anomaly amplitudes are displayed for different decades (P1: 1979-1988; P2: 1989-1998; P3: 1999-2008, P4: 2009_ 2016). The dominance of anomalous low sea ice area fluxes during the first decade is reflected as an asymmetric distribution pattern in frequency (Fig. 4a), with a larger number of months decreasing to the negative anomaly side. Comparatively, for the following three periods (Fig. 4b-d), the distribution pattern begins to become more symmetric, mainly because of the growing number of months with positive anomaly fields.

To depict the decadal evolution in frequency distribution, the individual months for each period are binned into four groups with different anomaly amplitude ranges $(A \leq-1$, $-1<A \leq-0.5,0.5<A \leq 1, A>1)$ and shown as inset text in Fig. 4. The fraction is the ratio between the number of months affiliated with a specific range and the number of all months of the corresponding decadal period. In this case, there are 120 months for each of the first 3 decades and 96 months for the last. Specifically, during the first decade (P1) approximately $43 \%$ of the months have normalized anomaly values less than -0.5 , in contrast to only $15 \%$ of the months showing positive normalized values of greater than 0.5 (Fig. 4a). In comparison, during the following three periods (Fig. 4b-d), the fractions of months with significant negative normalized anomaly values less than -0.5 ( $-1<A \leq-0.5$ and $A \leq-1)$ plummet to less than $28 \%$, but $24 \%-30 \%$ of the months are observed to have a distinct positive anomaly value at least of 0.5 (i.e., $0.5<A \leq 1$ and $A>1$ ). In addition, the fraction changes for the extreme 


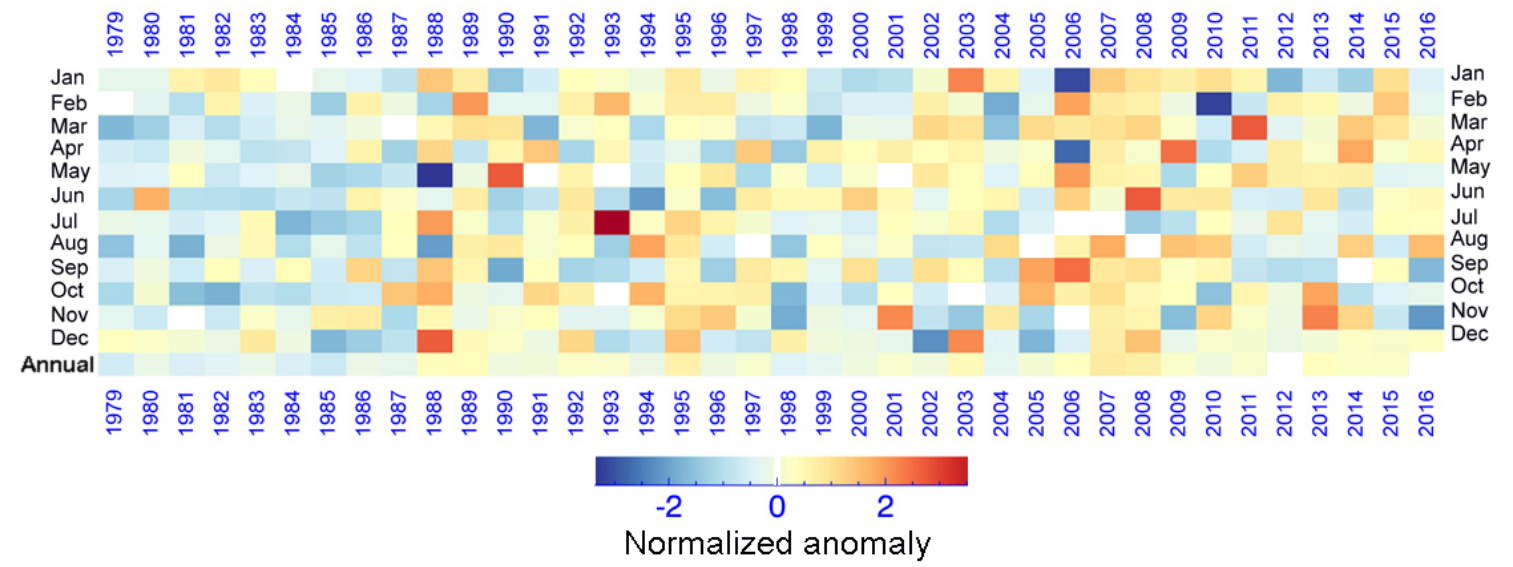

Figure 3. Normalized monthly anomaly fields of sea ice area flux. The anomaly field is calculated as the difference between the monthly estimate and the mean value of the same month computed over the period of interest. Then, the normalized anomaly field is obtained by dividing the monthly anomaly field by the standard deviation (SD) of the corresponding month over the 38-year period. The bottom row denotes the annual mean value of the normalized anomaly.
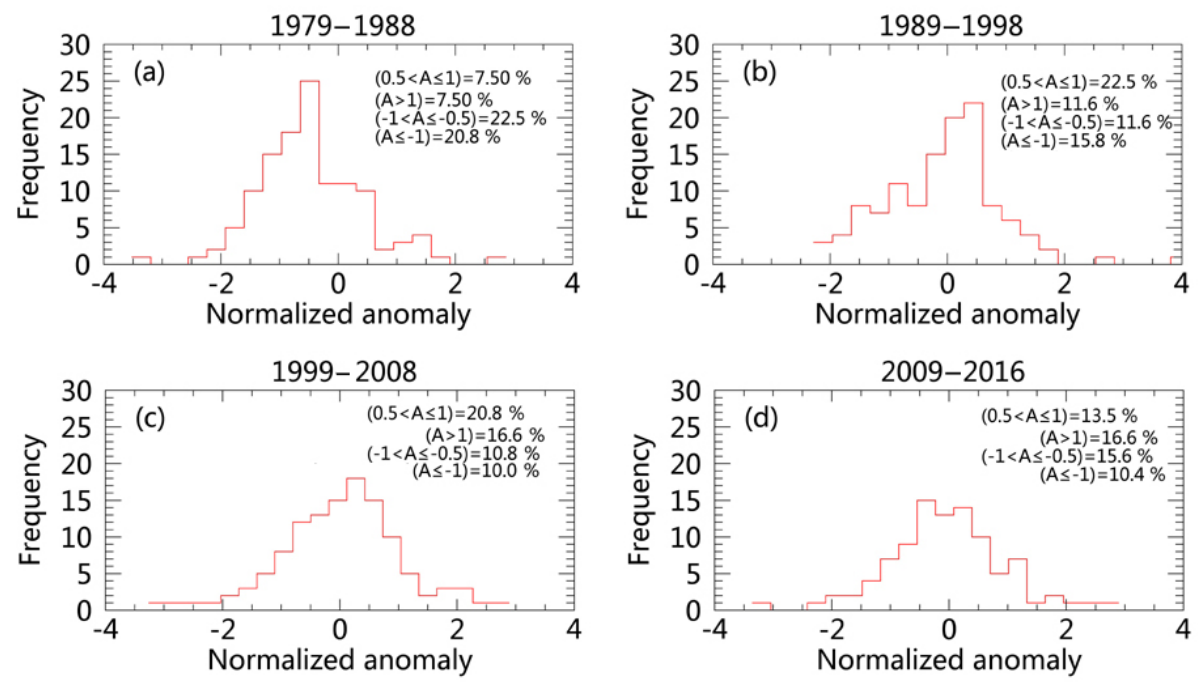

Figure 4. Frequency distribution histograms for months with different normalized anomalies in sea ice area flux in different decades. The fraction depicted as the percentage for each period, for example, $(0.5<A \leq 1)=7.5 \%$ as presented in panel (a), refers to the ratio between the frequency of the months sorted into the outlined range and the total number of months during the examined decades.

cases $(|A| \geq 1)$ remain relatively steady with time, varying between $26 \%$ and $29 \%$. However, the extreme low anomalies $(A \leq-1)$ decrease from $20.8 \%$ in $\mathrm{P} 1$ to $10.4 \%$, while the extreme high anomalies $(A>1)$ increase from $7.5 \%$ to $16.6 \%$. This shift in sea ice exchanges between the PA and the AA sectors may indicate a shift of atmospheric circulation toward a pattern facilitating sea ice export out of the PA side (Wu et al., 2005; Zhang et al., 2008; Jia et al., 2009)

The monthly trends in the sea ice area flux are listed in Table 2. The trend in percentage for each month denotes the fraction of the monthly trend estimate relative to the mean sea ice area flux for the corresponding month. Basically, all months (except for January) show positive trends, with a mean value of $2.52 \% \mathrm{yr}^{-1}$. The largest trend appears in $\mathrm{Au}-$ gust $\left(11.6 \% \mathrm{yr}^{-1}\right.$, significant at the $90 \%$ level), whereas the lowest occurs in January $\left(-3.67 \% \mathrm{yr}^{-1}\right.$, not statistically significant). The positive trend in August is mainly associated with an increasing trend in SIM in the transpolar drift stream (Fig. 5a). The negative trend in January is linked to the trend pattern from the Laptev Sea through the central Arctic to the east of the Beaufort Sea (Fig. 5b). The changes in SIM explain a major part $\left(R^{2}=0.98\right)$ of the trends and variability in sea ice area flux $\left(F_{\mathrm{m}}\right)$, and the remaining minor part is determined by the SIC changes, which induce negative contributions to the monthly flux trends during summer but small pos- 

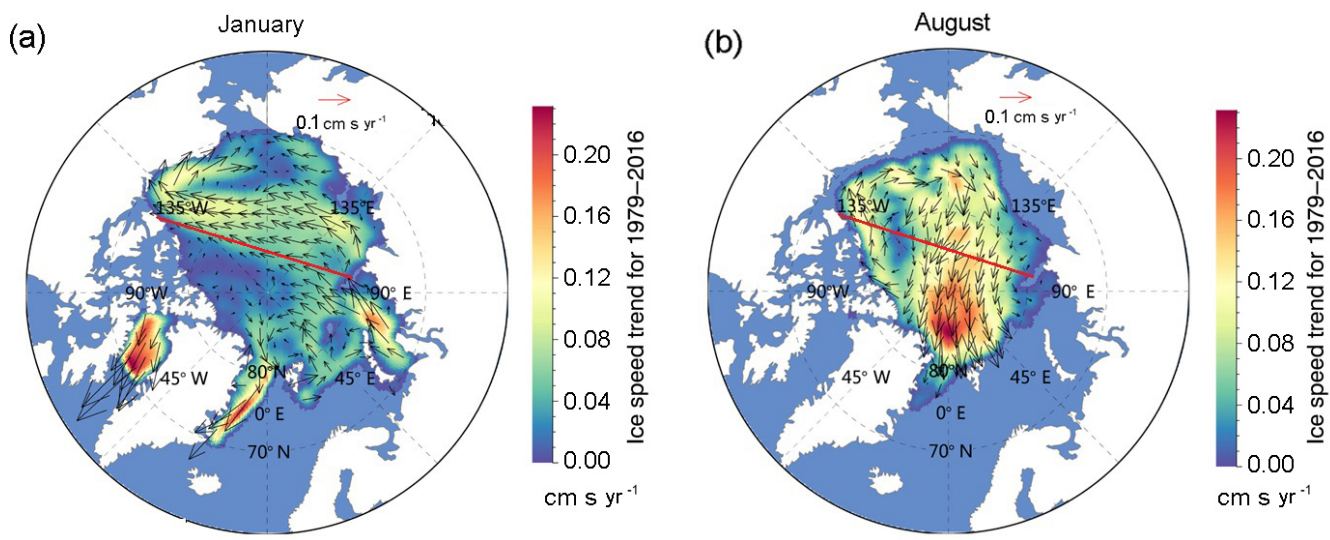

Figure 5. Sea ice motion trend in (a) January and (b) August. The magnitude of ice motion is indicated by background color and the length of arrows.

Table 2. Monthly trends for the sea ice area flux between PA and AA. The trends for the SIM and SIC fields over the fluxgate are also provided $\left(\% \mathrm{yr}^{-1}\right)$.

\begin{tabular}{|c|c|c|c|c|c|c|c|c|c|c|c|c|}
\hline & Jan & Feb & Mar & Apr & May & Jun & Jul & Aug & Sep & Oct & Nov & Dec \\
\hline$F_{\mathrm{m}}$ & -3.67 & 0.07 & $5.28^{* *}$ & $3.27^{*}$ & $2.68^{*}$ & $1.53^{*}$ & 1.17 & $11.6^{*}$ & 1.77 & $4.32 *$ & 1.77 & 0.43 \\
\hline SIM & -3.66 & 0.35 & $5.49^{* *}$ & $3.67^{*}$ & $2.94^{*}$ & $2.04^{*}$ & 0.53 & $10.44^{*}$ & 2.23 & $3.95^{*}$ & 2.47 & 1.20 \\
\hline SIC & 0.007 & 0.016 & 0.010 & 0.009 & -0.033 & -0.072 & -0.165 & -0.531 & -0.650 & -0.183 & -0.002 & 0.012 \\
\hline
\end{tabular}

Note: ${ }^{*}$ and ${ }^{* *}$ denote the significance level at $95 \%$ and $99 \%$, respectively.

itive contributions during winter months (December to April) (Table 2).

\subsubsection{Annual and seasonal sea ice area flux}

Figure 6 shows the estimates of the sea ice area transport for different seasons and years between the two sectors. The average annual sea ice export of $0.51( \pm 0.314) \times 10^{6} \mathrm{~km}^{2}$ comprises the mean winter and summer contributions of $0.337( \pm 0.263) \times 10^{6} \mathrm{~km}^{2}$ (or $\left.66 \%\right)$ and $0.173( \pm 0.153) \times$ $10^{6} \mathrm{~km}^{2}$ (or $34 \%$ ), respectively. The number after the sign " \pm " denotes the standard deviation of 38-year sea ice area flux. Annually, sea ice area flux peaked at $1.089 \times 10^{6} \mathrm{~km}^{2}$ in $2007 / 2008$ and set a record low of $-0.107 \times 10^{6} \mathrm{~km}^{2}$ in $1984 / 1985$. Seasonally, the winter sea ice exports vary between $-0.152 \times 10^{6} \mathrm{~km}^{2}(1998 / 1999)$ and $0.848 \times 10^{6} \mathrm{~km}^{2}$ (2013/2014), whereas the summer ice flux fluctuates within a range from $-0.166 \times 10^{6} \mathrm{~km}^{2}(1981)$ to $0.559 \times 10^{6} \mathrm{~km}^{2}$ (2006). The negative (positive) sea ice area flux as mentioned above points to a net sea ice inflow (outflow) from the AA to PA side (from the PA to AA side).

Over the 38-year period, significant positive trends are observed for the sea ice area fluxes during the summer and winter seasons (Fig. 6). Over the 38-year period, the winter sea ice export exhibits a positive trend of $0.009 \times 10^{6} \mathrm{~km}^{2} \mathrm{yr}^{-1}$ (i.e., $2.72 \% \mathrm{yr}^{-1}$, significant at a $95 \%$ level), and the summer export increases at a rate of $0.004 \times 10^{3} \mathrm{~km}^{2} \mathrm{yr}^{-1}$ (i.e., $2.40 \% \mathrm{yr}^{-1}$, significant at a $90 \%$ level). Together, they con-

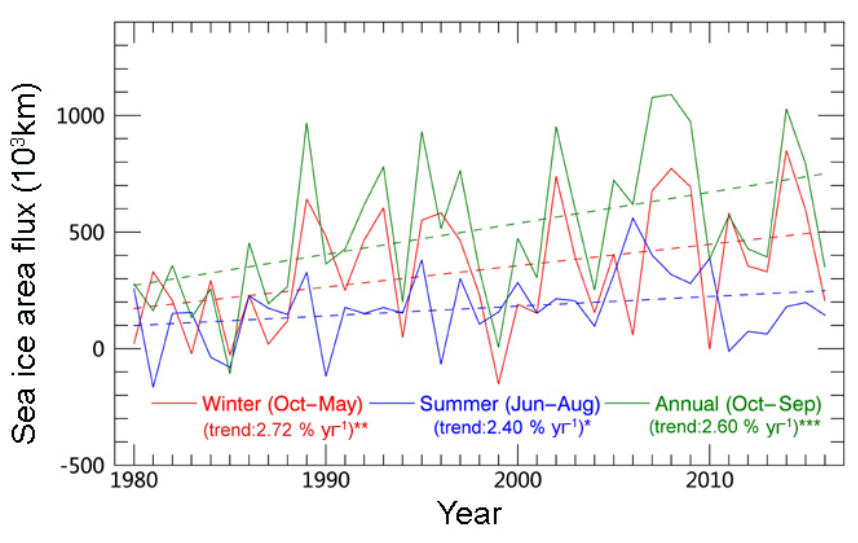

Figure 6. Annual and seasonal sea ice area fluxes between the PA and AA sectors over the period 1979-2016. The annual ice flow (annual cycle) is shown by the green line. Summer (from June through September) and winter (from October through May) fluxes are denoted with blue and red lines, respectively. The dashed lines representing the linearly fitted trends are obtained through the application of the least-squares method. The labels *,**, and *** correspond to the significance at the levels of $90 \%, 95 \%$, and $99 \%$, respectively.

tribute to an upward trend in annual sea ice area flux of $0.013 \times 10^{6} \mathrm{~km}^{2} \mathrm{yr}^{-1}$ (i.e., $2.61 \% \mathrm{yr}^{-1}$, significant at a $99 \%$ level). The trend within the parentheses, expressed as percentage per year, is taken by dividing the trend estimate by the corresponding 38-year mean estimate of sea ice area flux. 
The sharp increase since 1989 and onward for the winter export (Fig. 6), in contrast to the preceding period 1979-1988, preconditions for a significant positive trend in the winter as well as annual fields of outflow. Nonetheless, the summer ice area flux features a gradual increase over the whole period, with anomalously large ice export occurring between 2006 and 2010 (approximately $0.310 \times 10^{6} \mathrm{~km}^{2}$, on average), which is favorable for the maintenance of the overall positive trend in summer.

Due to the extensive coverage in longitudes and latitudes across the investigated fluxgate $(2840 \mathrm{~km})$, regional variations in the trend of the across-gate sea ice area flux fields are expected. Broadly, the Arctic sea ice circulation is characterized by the Beaufort Gyre (BG) and transpolar drift stream (TDS). How does the SIM trend vary in these two regimes? To answer this question, we not only present the overall pattern of spatial distribution of SIM trends over the entire Arctic Ocean (Fig. 7), but also depict the details of the cross-gate SIM trends in fields (Fig. 8). Figure 7 shows that SIM increases in the BG and TDS regimes during both winter (Fig. 7a) and summer (Fig. 7b) seasons. In particular, the increasing SIM trends in the narrow southern arm of the BG regime appear in winter (Fig. 7a) and summer (Fig. 7b) The SIM trends during winter (summer) of approximately $0.12 \mathrm{~cm} \mathrm{~s}^{-1} \mathrm{yr}^{-1}\left(0.11 \mathrm{~cm} \mathrm{~s}^{-1} \mathrm{yr}^{-1}\right)$ (i.e., approximately $0.10 \mathrm{~km} \mathrm{yr}^{-1}$ ) over the southern arm of the BG lead to a reduced net sea ice export (i.e., more ice inflow) through the west end of the fluxgate (Fig. 8a and b). The increasing SIM in the TDS is $0.07 \mathrm{~cm} \mathrm{~s}^{-1} \mathrm{yr}^{-1}\left(0.04 \mathrm{~cm} \mathrm{~s}^{-1} \mathrm{yr}^{-1}\right)$ (i.e., approximately $\left.0.06 \mathrm{~km} \mathrm{yr}^{-1}\left(0.03 \mathrm{~km} \mathrm{yr}^{-1}\right)\right)$ during the winter (summer) season. Therefore, increasing sea ice outflow through the TDS is compensated for by sea ice inflow associated with the BG. Compared with that in winter (Figs. 7a or $8 \mathrm{a}$ ), the sea ice trend in the TDS (Figs. $7 \mathrm{~b}$ and $8 \mathrm{~b}$ ) shifts its central axis to parallel to the prime meridian. Overall, the SIM trend pattern appears to form an Arctic-wide anticyclonic mode. As discussed below, this mode has crucial meanings for the retreat of sea ice in the Pacific sector during summer.

\subsection{Melting sea ice within the Pacific sector in summer}

Sea ice melting is a sensitive indicator reflecting the warmer Arctic climate. An estimate of melting area of sea ice (dotted-dashed line in Fig. 9) is obtained as the difference between the observed sea ice area loss in the PA (red line in Fig. 9) and the sea ice area flux through the fluxgate (blue line in Fig. 9) during the summer season (June-September). Over the 38-year period, the mean melting area is $1.66 \times$ $10^{6} \mathrm{~km}^{2}$, with a distinct variation from $0.68 \times 10^{6} \mathrm{~km}^{2}(1980)$ to $3.49 \times 10^{6} \mathrm{~km}^{2}$ (2012). Noticeably, the PA sector seems to have been shifted into a new era from 2007 onward, with large ice melting of $2.70 \times 10^{6} \mathrm{~km}^{2} \mathrm{yr}^{-1}$ during the post-2007 period compared with $1.70 \times 10^{6} \mathrm{~km}^{2} \mathrm{yr}^{-1}$ for the period before 2007. In contrast, the sea ice area in the AA sector dur- ing summer scarcely changed before 2008 (the first three rows in Fig. 9). AA is located at higher latitudes where less melting is expected compared the PA. However, recent sea ice area changes reveal a shrinkage of sea ice area approximately $0.28 \times 10^{6} \mathrm{~km}^{2}$ within the AA sector in September 2012 to 2013 (Fig. 9). The sea ice loss within the AA may be more evident if the starting date of melting becomes earlier (Stroeve et al., 2014) and melting intensity is reinforced by the positive feedback mechanism of ice albedo (Perovich et al., 2007, 2008; Screen and Simmonds, 2010) and/or if sea ice outflow through the Fram Strait is enhanced (Kwok et al., 2013; Bi et al., 2016; Smedsrud et al., 2017).

With the sea ice area budget shown in Fig. 9, we quantify the relative contribution to sea ice area changes in summer due to the advection and melting processes over the period of 1979-2016 (i.e., melting $(M)=$ observed area change $(O)$-advection $(A))$. As a fractional contribution, the advection and melting processes, on average, account for $9.6 \%$ (i.e., $A / O \times 100 \%$ ) and $90.4 \%$ (i.e., $M / O \times 100 \%$ or $(A-O) / O \times 100 \%)$, respectively, of the observed ice area loss within the PA sector during summer months. Interannual variability in fractions is distinct, as suggested by the standard deviation of approximately $9 \%$. However, no significant trend is identified in the fractions of sea ice area in connection with the two processes (Fig. 10). The smallest (largest) fraction of $72.6 \%(110.2 \%)$ in the sea ice area change due to melting was observed in 2006 (1979), along with the largest (smallest) fraction of $27.4 \%(-10.2 \%)$ due to sea ice area advection (Fig. 10). The negative fraction with respect to advection suggests a net inflow from the AA to PA side. In this case, the actual melting area $(O-A)$ is thus larger than the directly observed area changes $(O)$, causing a melting fraction greater than $100 \%$. Over the examined period, the cases with a net increase in advective ice area took place before 1985.

The trend of melting sea ice area within the PA is apparent over the 38-year period (Fig. 11), with an overall positive trend of $3.20 \% \mathrm{yr}^{-1}$ (significant at the $99 \%$ level) (Fig. 11). Since the mid 1990s, sea ice melting within the PA has been continually enhanced (Fig. 11), which is associated with Arctic amplification (Screen and Simmonds, 2010). Decadal variability is also significant. The greatest increase of $7.48 \% \mathrm{yr}^{-1}$ (significant at the $99 \%$ level) occurred in the third decade (1999-2008), whereas the remaining 3 decades show moderate or even negative trends.

Additionally, note that the day of year (DOY) of the minimum sea ice area in the PA sector displays an overall positive trend of $0.29 \mathrm{~d} \mathrm{yr}^{-1}$ (Fig. 12). The trend implies a gradually delayed occurrence of the DOY of the minimum sea ice area in the PA. There are also decadal variations in this DOY. In particular, over the second (1989-1998) and third decades (1999-2008), the trends in DOY approach approximately 1.46 and $1.63 \mathrm{~d} \mathrm{yr}^{-1}$, respectively (Fig. 12). The overdue DOY is associated with the earlier beginning of the melting date (Stroeve et al., 2014) and the positive sea ice albedo 


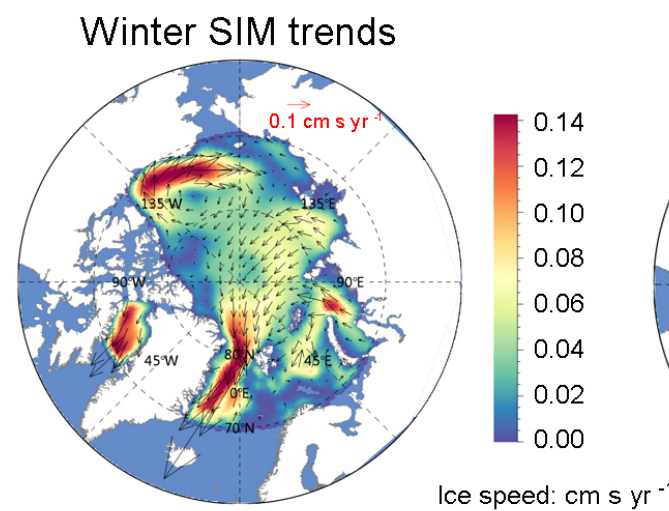

(a)

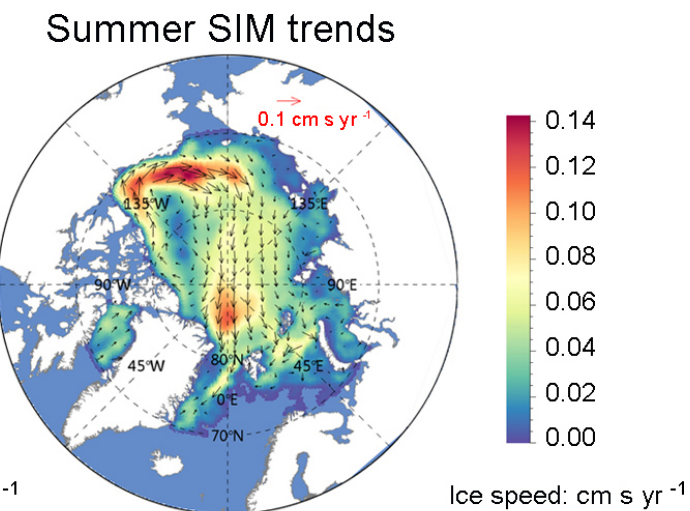

(b)

Figure 7. SIM trends during (a) winter (October-May) and (b) summer (June-September) over the period 1978/1979-2015/2016 and 1979_ 2016, respectively.
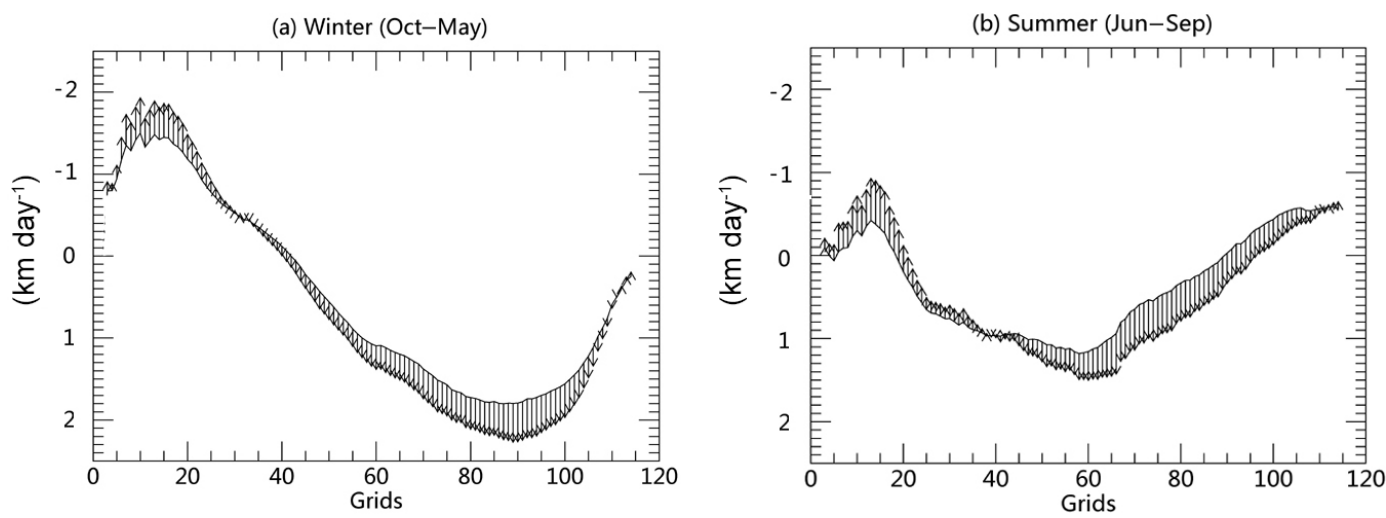

Figure 8. Cross-gate SIM climatology (black solid line) and trends (arrows) for (a) winter and (b) summer over the 38-year period. The left end represents for the North American side and the right the Eurasian side.

feedback loop (Perovich et al., 2008), which allows more heat to be absorbed in the area of ice loss, facilitates more melting of sea ice in the PA sector, and results in later occurrence of the minimum sea ice area. However, since 2009, the DOYs appear to have recovered to the former state in the 1980s (Fig. 12). This reversion can be explained by the withdrawal of the sea ice extent toward a position farther north at high latitudes (Figs. 9 and 11), where freezing usually starts earlier in comparison with areas at southern latitudes (Stroeve et al., 2014).

\section{Discussion}

Wind forcing has been significant in modulating the sea ice variability in summer (Ogi et al., 2016). As an example, sea ice depletion induced by the summer melting process is connected to the wind forcing, which can help to cause a warmer Arctic climate through the advection of warmer and moister air from the south (Wang et al., 2005; Zhang et al., 2013; Lee et al., 2017). The Arctic-wide wind forcing is linked to largescale atmospheric circulation patterns (Zhang et al., 2008; Overland and Wang, 2010; Stroeve et al., 2011). Hence, the connection between the sea ice area loss in the PA sector and three typical atmospheric indices (AO, NAO, and DA) is assessed here. NAO and $\mathrm{AO}$ represent the dominant atmospheric circulation modes in guiding sea ice movement and Fram Strait export before 1994 (Rigor et al., 2002; Nakamura et al., 2015), while the DA seems to play a leading role over the latter period after 1995 (Wang et al., 2005). Here our objective is to examine how the sea ice variability due to advection and melting processes is quantitatively related to the interannual and decadal changes in these atmospheric modes. Furthermore, the potential impacts on sea ice loss in related climatic variables (SAT, SLP, and PW) coupled with different atmospheric circulation patterns are highlighted.

Overall, the interannual variability for the three indices is large, and two indices, NAO and DA, reveal significant trends during summer (Fig. 13). Over the investigated 38year period, the sea ice area reduction in summer within the 

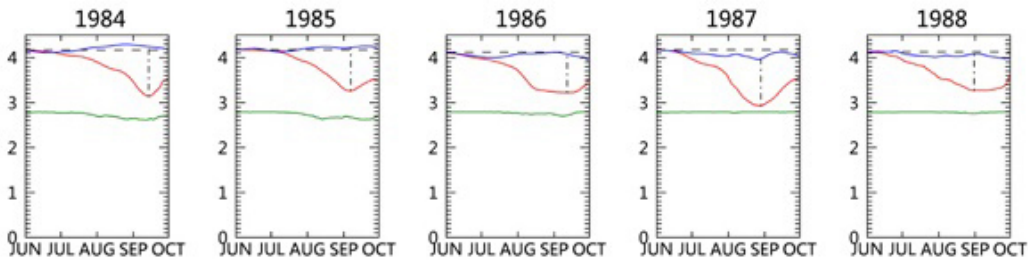

1997
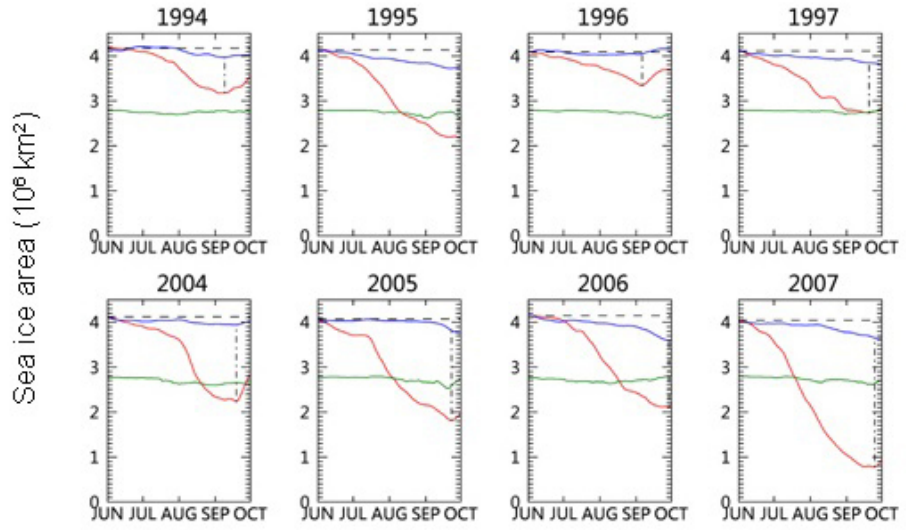

2005
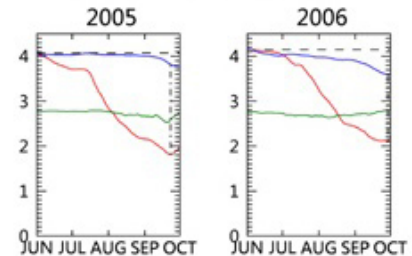

2012

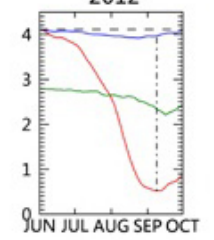

2013

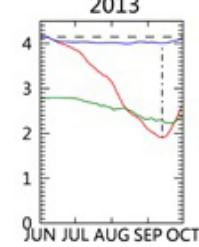

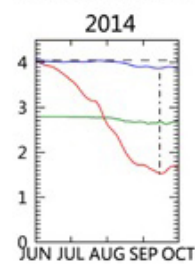
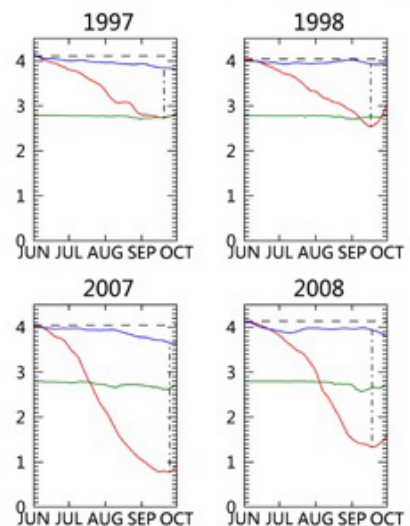

SUN JUL AUG SEE
2008

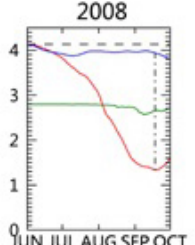

2015
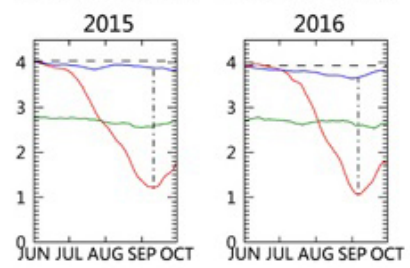

\section{Legend}

Sea ice area in

Atlantic sector

Sea ice area in

Pacific sector

Sea ice area flux

from $P A$ to $A A$

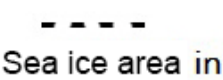

June 1

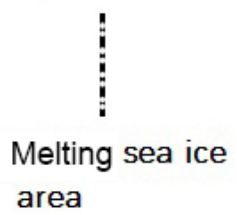

area

Figure 9. Selected daily changes in sea ice areas within the PA (red) and AA (green) during summer (June-September) for the period 19792016. The horizontal dashed line represents the sea ice area in the PA on 1 June, which is used as a benchmark to measure the sea ice area changes due to melting. The cumulative daily sea ice area flux, with reference to the top dashed line, is shown as a blue line. The melting sea ice area, denoted by the vertical dotted-dashed line, is taken as the difference between the total decline in sea ice area within the PA and the accumulated flux through the gate.

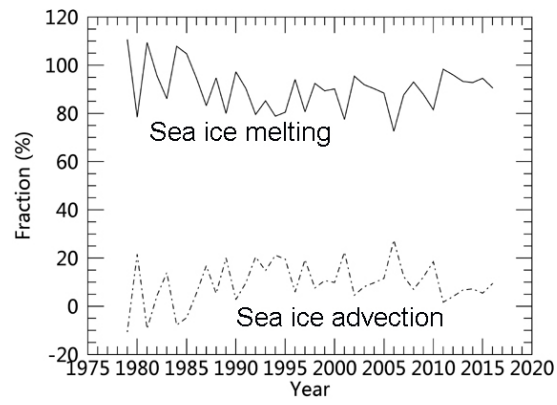

Figure 10. Fractions of sea ice area loss in the PA sector that are related to the sea ice melting and advection processes.

PA seems to have been slightly influenced by AO fluctuations, with a low correlation coefficient $(R)$ of -0.24 (Table 3). Separately, the sea ice area variations caused by advection and melting are barely attributable to the $\mathrm{AO}$ effects (Table 3). Therefore, in the following, we focus our analysis on the effects of the atmospheric circulations associated with

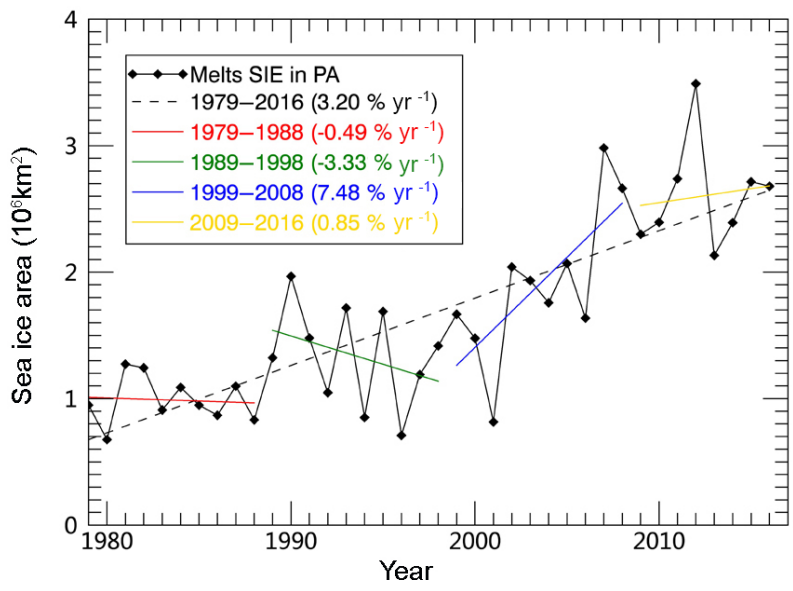

Figure 11. Time series for melting sea ice areas within PA.

NAO and DA, which show relatively strong correlations with the changes in sea ice area in the PA (Table 3). 


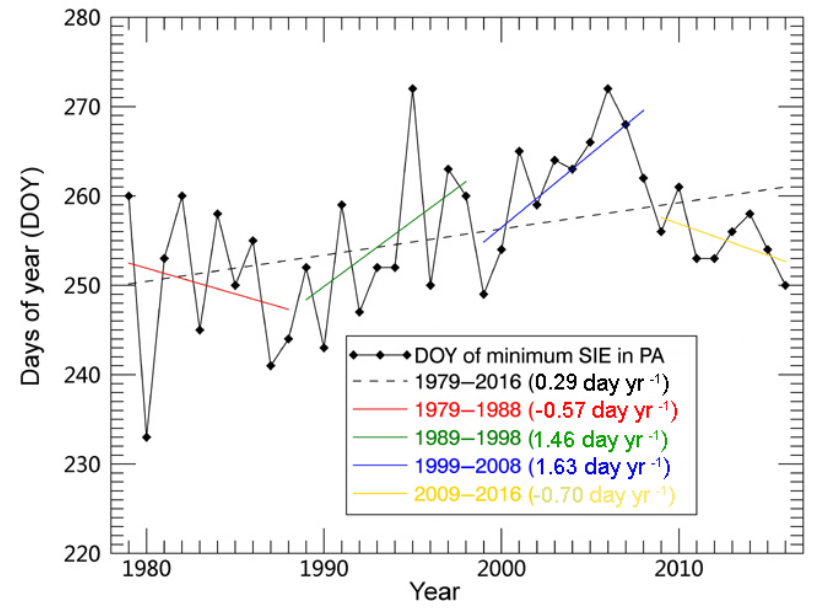

Figure 12. Day of year (DOY) of the annual minimum sea ice area in PA.

Table 3. Correlations between summer mean atmospheric index and total sea ice area loss, and sea ice area decline due to melting and advection processes over the period 1979-2016.

\begin{tabular}{lrrr}
\hline $\begin{array}{l}\text { Atmospheric } \\
\text { index } \\
\text { (summer mean) }\end{array}$ & $\begin{array}{r}\text { Melting } \\
\text { sea ice }\end{array}$ & $\begin{array}{r}\text { Net sea ice } \\
\text { advection }\end{array}$ & $\begin{array}{r}\text { Total ice retreat } \\
\text { (melting + } \\
\text { advection) }\end{array}$ \\
\hline AO & -0.28 & 0.14 & -0.24 \\
NAO & -0.47 & -0.18 & -0.46 \\
DA & 0.55 & 0.74 & 0.63 \\
\hline
\end{tabular}

The influence of NAO-associated atmospheric circulation in winter on sea ice changes in summer has been broadly documented (Kwok, 2000; Jung and Hilmer, 2001; Parkinson, 2008), which is especially clear for the period from the late 1980s to early 1990s (Jung and Hilmer, 2001) when NAO was in its peak positive phase. In this study, the summer NAO is negatively correlated with the summer retreat of sea ice area within the PA sector $(R=-0.46)$ over the 38 -year period. Table 2 shows a stronger connection with the sea ice area change due to melting $(R=-0.47)$ than with the sea ice area loss in relation to advection $(R=-0.18)$. That is, a negative NAO in summer would favor more sea ice melting and hence less ice coverage.

As there is a clear negative trend in the summer mean NAO index (Fig. 13b), one may wonder how the summer NAO index trend is related to the increasing loss of sea ice within the PA sector. As shown in Fig. 14g, the NAO-associated SLP distribution pattern, with a greater SLP in the western Arctic near the Canadian Archipelago, is favorable for a pattern of anticyclonic atmospheric circulation within the PA. Such a clockwise pattern of atmospheric circulation is hypothesized to push more ice from the eastern and northern Beaufort Sea to the western and southern Chukchi Sea (Figs. 7b and $8 \mathrm{~b}$ ), where extensive sea ice melting has been commonly observed (Kwok, 2008a). The moderate negative correlation between NAO and melting sea ice area $(R=-0.47)$ corroborates this hypothesis.

The overall association between sea ice area variability and the DA index is comparatively robust $(R=0.63)$. Considering the clear positive trend in DA (1979-2016) (Fig. 13c), the SLP changes explained by the DA trend are characterized by a dipole pattern with one action center over the Barents and Laptev seas and the other center of action appearing on the opposite side over the Canadian Archipelago and Greenland (Fig. 14f). In fact, the spatial distribution for the DA-associated SLP changes over the Arctic basin is broadly consistent with those for the actual SLP changes (Fig. 14e), except for a prominent negative SLP center over the North Pacific and an enhanced positive SLP center over Greenland. With this type of SLP distribution, the DA-associated winds induce strengthened meridional ice advection through the TDS within the central Arctic (Figs. 5, 6b in Sect. 3.1.3). A more rapid transpolar advection of sea ice is thus responsible for the observed increasing trend in the sea ice outflow from the PA to the AA sectors (Fig. 7b). In addition, with such DA-associated SLP changes, more warmer air from the southern areas can be advected into and warm the SAT in the northern Arctic, finally augmenting the ice melting process (Zhang et al., 2013; Lee et al., 2017). Indeed, an SAT ridge centered on the East Siberian Sea is observed (Fig. 14b). As a response, the cold air of the high-latitude Arctic origin is pushed out toward the southern areas, reducing the local SAT over the eastern Greenland Sea, Barents Sea, and Kara Sea regions (Fig. 14b).

Associated with the DA-associated SLP distribution pattern, the emergence of enhanced BG circulation is identified in the Beaufort Sea (Fig. 14f). In particular, the sea ice drifts in the southern arm of the BG regime are largely strengthened (Fig. 7b), which contributes to the large inflow of sea ice to the southern Beaufort Sea (Fig. 8b), where sea ice undergoes dramatic melting processes in summer as indicated by the remarkable SAT increase there (Fig. 14a). This coupled mechanism between dynamic (advection) and thermodynamic (melting) processes resembles that caused by the NAO. As a consequence, the depletions in sea ice in summer due to both melting and advection are relatively strongly correlated to the DA index of summer, with $R$ values of 0.55 and 0.74 , respectively, over the entire period (Table 3 ).

Since AO shows a negligible trend (Fig. 13a), the 38-year climatic changes related to AO are insignificant (Fig. 14d, $\mathrm{h}$, and i) and smaller in magnitude compared to the DAand NAO-associated changes. The NAO pattern is conventionally deemed a regional index, representing parts of the broader AO pattern. However, NAO-associated SLP changes (Fig. 14g) show a stronger gradient across the fluxgate than that of AO-associated SLP (Fig. 14h), which would favor more sea ice outflow from the PA to AA sectors. In comparison with NAO (Fig. 14g), the AO-associated SLP distribution shows a much weaker gradient across the Arctic Ocean 

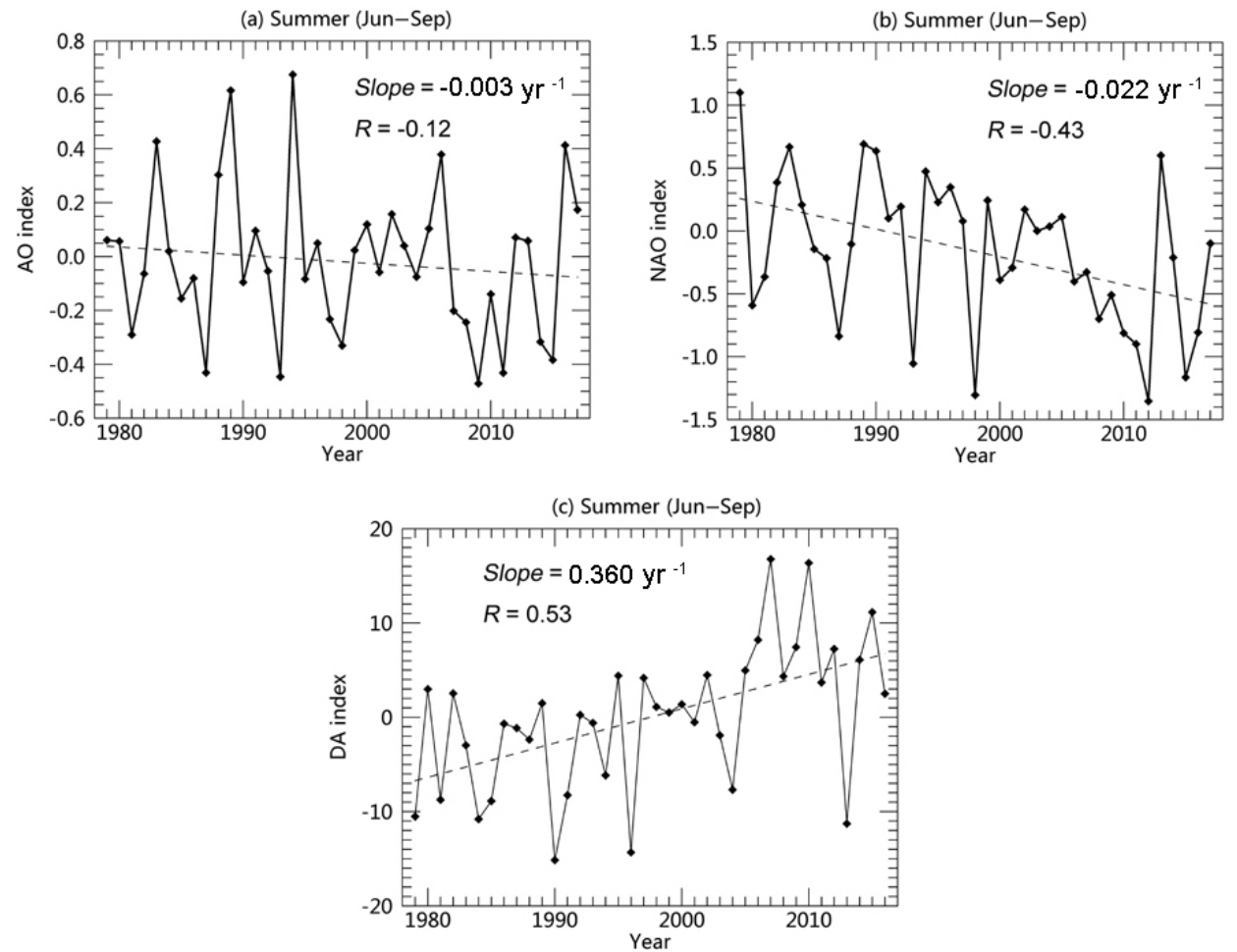

Figure 13. Variations in and trends of the mean atmospheric indices in summer (June-September), including (a) the AO, (b) the NAO, and (c) the DA index. The linear trends of NAO and DA indices are both significant at the $95 \%$ significance levels according to the $t$-test method, while the $\mathrm{AO}$ index reveals an insignificant trend.

Table 4. Correlations between summer mean atmospheric index and sea ice minimum area in the PA sector for the different decades and the whole 38-year period.

\begin{tabular}{lrrrrr}
\hline Summer & P1 & P2 & P3 & P4 & Overall \\
(Jun-Sep) & $1979-1988$ & $1989-1998$ & $1999-2008$ & $2009-2016$ & $1979-2016$ \\
\hline AO & 0.57 & 0.46 & 0.39 & -0.34 & 0.24 \\
DA & -0.03 & -0.16 & -0.68 & -0.45 & -0.63 \\
NAO & 0.16 & 0.24 & 0.23 & 0.87 & 0.46 \\
\hline
\end{tabular}

(Fig. 14h), although it may contribute to the sea ice advection from the Pacific side to the Atlantic side. As a result, lower correlations between $\mathrm{AO}$ and sea ice melting and advection processes are expected, with $R=-0.28$ and 0.14 (Table 3). However, these small overall correlations do not necessarily imply that AO plays no role in causing sea ice variations. For instance, throughout the examined periods, $\mathrm{AO}$ exerted more influences on sea ice changes for the earlier 2 decades (1979-1998), with $R=0.57$ and 0.46 (Table 4).

The temporally varying association between atmospheric circulation and sea ice drift reflects Arctic climate changes. How does the linkage vary with time? Does it remain stable? To answer these questions, correlations between different summer mean atmospheric indices and minimum sea ice areas in the PA sector over different decades are obtained (Table 4). The AO effects are relatively unstable, imposing clear and decreasing positive effects over the first 3 decades but reversing to a negative moderate impact in the last period (P4) (Table 4). A clear association with DA arises during the latter two periods: P3 (1999-2008) and P4 (2009-2016). In contrast, the NAO index appears to have a significant impact only during the last period (2009-2016) (Table 4).

PW serves as an important indicator of Arctic climatic conditions. In view of the distribution of PW changes (Fig. 14i), we find it broadly agrees with that of SAT in the PA sector (Fig. 14a). For example, over the Siberian marginal seas, warmer SATs accompany more PWs. If the PW constituents drop to the surface as rain during a warming summer, they may benefit the melting process of the local ice/snow surface by lowering the surface albedo of ice/snow. Compared with the NAO-associated changes (Fig. 14k), the spatial distributions of DA-associated SAT (Fig. 14b) and 


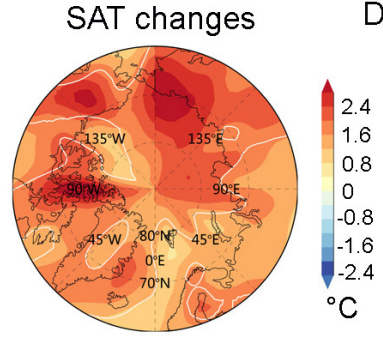

(a)

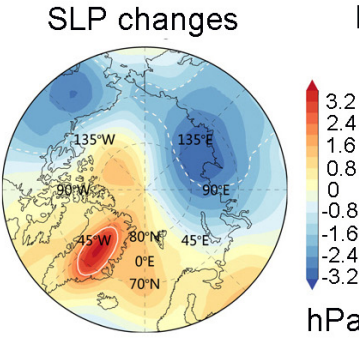

(e)

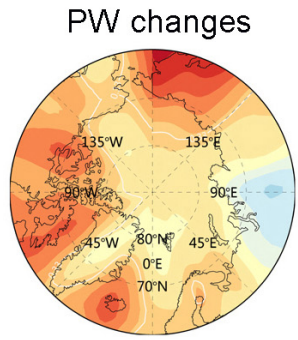

(i)

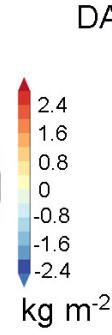

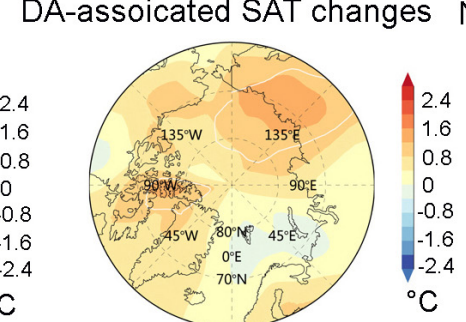

(b)

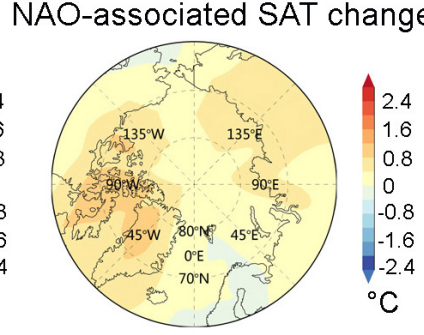

(c)

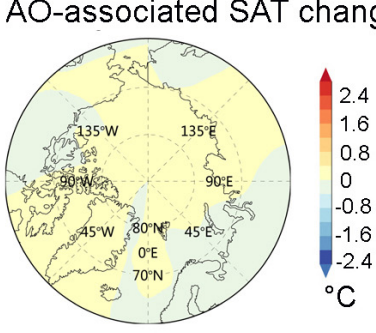

(d)

DA-associated SLP changes NAO-associated SLP changes

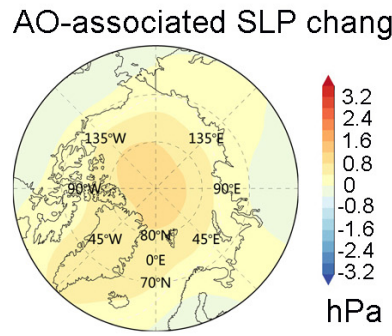

(h)

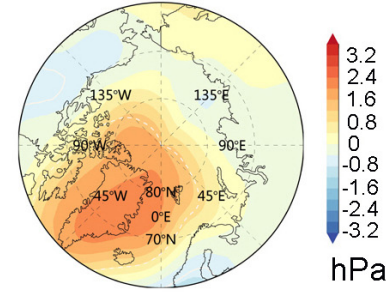

(g)

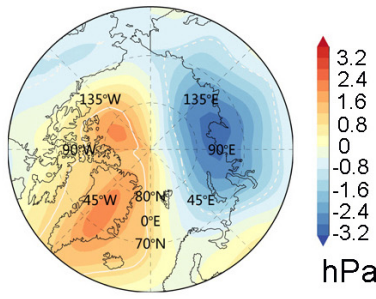

(f)

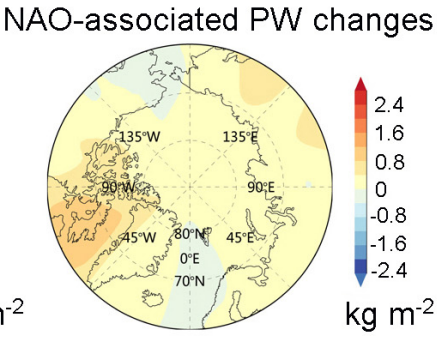

(k)

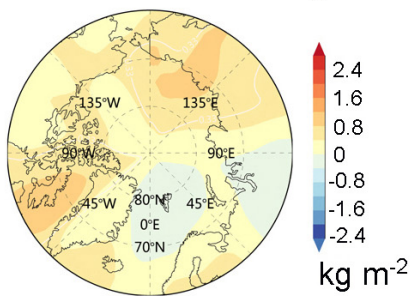

(j)

Figure 14. The changes in typical climate variables (SAT, SLP, and PW) over the 1979-2016 period (the first column, panels a, e, and i). The change is obtained by multiplying the trend estimate (regression map) and the time span of the period (i.e., 38 years). The regressions of these climatic variables on the DA (the second column, panels $\mathbf{b}, \mathbf{f}$, and $\mathbf{j}$ ), NAO (the third column, panels $\mathbf{c}, \mathbf{g}$, and $\mathbf{k}$ ), and AO (the fourth column, panels $\mathbf{d}, \mathbf{h}$, and $\mathbf{l}$ ) are also presented.

PW changes (Fig. 14j) are, to a greater degree, consistent with those of the summer SIC trends (Fig. 15), particularly over the area throughout the marginal seas in the PA sector, such as the Beaufort Sea, Chukchi Sea, East Siberian Sea, and Laptev Sea where the rates of sea ice area decline approach $2.0 \% \mathrm{yr}^{-1}$. Conversely, we note that the magnitudes of SAT (or PW) changes in connection with the DA and NAO are far less comparable to the total SAT (or PW) changes, and similarity in spatial distribution between Fig. 14b and c (or Fig. $14 \mathrm{j}$ and $\mathrm{k}$ ) is not readily identifiable. This result occurs because, aside from the effects of atmospheric circulation, other mechanisms also play important roles in the large and broad increases in SAT and thus PW over the Arctic, such as the sea ice albedo feedback loop, the intrusion of warmer Pacific-Atlantic Ocean water (Shimada et al., 2006; Tverberg et al., 2014; Alexeev et al., 2017), cloud feedback (Liu et al., 2008; Schweiger et al., 2008), and the changes in strength of the Atlantic meridional overturning current (AMOC) (Chen and Tung, 2018).

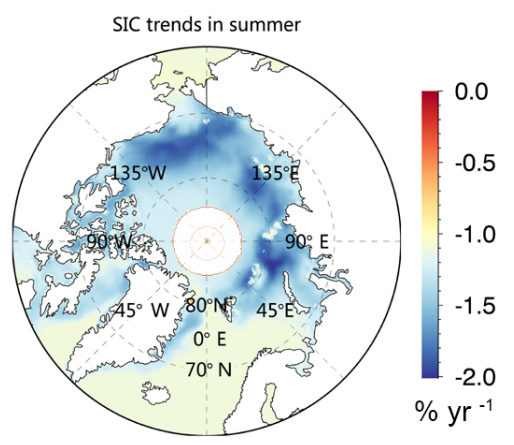

Figure 15. Summer SIC trends over the period 1979-2016.

To summarize this section, we found different atmospheric forcing patterns exert varying influences on summer sea ice variability. Overall, the connections are relatively strong between sea ice loss and DA $(R=0.63)$ and NAO $(-0.46)$, but fragile with $\mathrm{AO}(R=-0.24)$. In particular, the DA af- 
fects sea ice loss through both advection $(R=0.74)$ and melting $(R=0.55)$ processes, whereas the NAO acts prominently on the melting process $(R=-0.46)$. This is consistent with previous arguments that the DA plays a more vital role in promoting summer sea ice depletion (Jia et al., 2009). Furthermore, our analysis shows that the connections are not invariant on a decadal scale, but are characteristic with a regime shift (Table 4). Accordingly, the linkage between atmospheric forcing and sea ice loss is stronger during the earlier 2 decades (1979-1998) with AO and NAO, but more robust with DA for the latter 2 decades (1999-2016). Since DA is becoming a more favorable pattern for summer sea ice loss through both dynamic and thermodynamic forcing, the causes for its surface emergence and amplification remain unclear and need further investigation.

\section{Concluding remarks}

Using the new version (v3.0) of NSIDC products (SIM and SIC), we quantify the contributions of the advection and melting processes to the sea ice retreat within the PA sector over the period 1979-2016. A synoptic view of their 38 -year variability and trends on different timescales is presented. Over this period, the annual (October to following September) mean sea ice export is $0.510( \pm 0.314) \times 10^{6} \mathrm{~km}^{2}$, with summer (June-September) and winter (October-May) outflows of $0.173 \times 10^{6} \mathrm{~km}^{2}$ (or $34 \%$ ) and $0.337 \times 10^{6} \mathrm{~km}^{2}$ (or $66 \%$ ), respectively. A positive trend for the annual sea ice outflow is also identified, at approximately $0.013 \times$ $10^{6} \mathrm{~km}^{2} \mathrm{yr}^{-1}$ (or $2.08 \% \mathrm{yr}^{-1}$ ), which is attributable to the increasing export of $0.009 \times 10^{6} \mathrm{~km}^{2} \mathrm{yr}^{-1}$ (or $2.72 \% \mathrm{yr}^{-1}$ ) in winter and increasing outflow of $0.004 \times 10^{6} \mathrm{~km}^{2} \mathrm{yr}^{-1}$ (or $2.43 \% \mathrm{yr}^{-1}$ ) in summer. At the same period, sea ice area loss linked to the melting in summer, on average, amounts to $1.66 \times 10^{6} \mathrm{~km}^{2}$, with a significant positive trend of $0.053 \times$ $10^{6} \mathrm{~km}^{2} \mathrm{yr}^{-1}\left(3.20 \% \mathrm{yr}^{-1}\right)$. Further, we examine the relative roles of ice advection and melting in the decline of sea ice within the PA where dramatic sea ice retreat has occurred in summer during recent years. As a percentage, the sea ice depletions in the PA due to the advection and melting processes account for $9.6 \%$ and $90.4 \%$, respectively.

The linkage between sea ice loss and wind forcing associated with different large-scale atmospheric circulations during the summer season is explored. Overall, the $\mathrm{AO}$ is weakly connected to the sea ice loss on the PA sides, while the NAO is moderately correlated with the sea ice decline caused by melting. In contrast, the DA shows a more robust connection with the sea ice decrease in the PA through influence on both sea ice melting and advection. Dynamically, the DAassociated SLP conveys heat and moist air from the south to the north, resulting in the increasing SAT and PW over the marginal seas of the PA sector and contributing to the significant sea ice retreat. In addition, the positive trend in the DA induces stronger meridional wind forcing over the trans- polar stream, leading to increased sea ice outflow and more ice decline in the PA. Thermodynamically, both the DA and NAO indices are associated with a strengthened anticyclonic SLP pattern over the southern Beaufort Sea. This feature will promote the westward transport of sea ice from the Canadian Basin to the south of the Beaufort Sea and Chukchi Sea where extensive melting sea ice has been detected in summers during the recent decade. By contrast, AO-associated sea ice changes due to melting and advection processes are not distinct, although temporally robust correlation is expected (Table 4).

The significant sea ice retreat also plays a crucial role in triggering regional responsive feedback in the atmosphere (Overland and Wang, 2010), as indicated by the warmer SAT (Fig. 13a) and decreased SLP (Fig. 13d) observed on the broad Siberian Arctic Ocean side. Therefore, if the current distinct sea ice loss on the Pacific-Arctic Ocean persists, the diminishing SLP in areas over the Laptev Sea, one of the centers of action of the DA, will further enhance the positive DA trend. Consequently, stronger dynamic (advection) and thermodynamic (melting) effects associated with the DA on sea ice retreat within the PA sector are probably foreseen in the predictable future.

Data availability. NSIDC sea ice motion is available at http://nsidc.org/data/NSIDC-0116 (Tschudi et al., 2019a). NSIDC sea ice concentration employed to calculate sea ice area flux is available at http://nsidc.org/data/NSIDC-0079 (Comiso, 2017). The reanalysis data of SLP, SAT, and PW are available at https: //www.esrl.noaa.gov/psd/cgi-bin/db_search/DBListFiles.pl?did= 195\&tid=72450\&vid=676, https://www.esrl.noaa.gov/psd/cgi-bin/ db_search/DBListFiles.pl?did=195\&tid=72451\&vid=3083, and https://www.esrl.noaa.gov/psd/cgi-bin/db_search/DBListFiles.pl? $\mathrm{did}=195 \& \mathrm{tid}=73261 \& \mathrm{vid}=1848$, respectively $\quad$ (Kalnay, 2019a, b, c). Climatic variables AO and NAO are available at http://www.cpc. ncep.noaa.gov/products/precip/CWlink/daily_ao_index/ao.shtml (Thompson and Wallace, 2019), and http://www.cpc.ncep.noaa. gov/products/precip/CWlink/pna/nao_index.html (Hurrell, 2019).

Author contributions. HB and QY led the analysis and integrated the data. XL, LZ, YW, and YL process the sea ice motion and sea ice concentration data. HB, XL, and LZ performed the area flux calculations. HB, QY, and HH drafted the paper. All authors discussed the results and commented on the paper.

Competing interests. The authors declare that they have no conflict of interest.

Acknowledgements. We thank for the following organizations for providing the data used in this study. NSIDC provided the satellitederived ice motion and concentration data, and the National Centers for Environmental Prediction/National Center for Atmospheric Research (NCEP/NCAR) provided the reanalysis product. 
Financial support. This research has been supported by the National Natural Science Foundation of China (grant no. 41406215) and the NSFC Shandong Joint Fund for Marine Science Research Centers (grant no. U1606401).

Review statement. This paper was edited by John Yackel and reviewed by two anonymous referees.

\section{References}

Alexeev, V. A., Walsh, J. E., Ivanov, V., Semenov, V. A., and Smirnov, A.: Warming in the Nordic Seas, North Atlantic Frankenstorms and thinning Arctic sea ice, Environ. Res. Lett., 12, 084011, https://doi.org/10.1088/1748-9326/aa7a1d, 2017.

Bi, H., Sun, K., Zhou, X., Huang, H., and Xu, X.: Arctic Sea Ice Area Export Through the Fram Strait Estimated From SatelliteBased Data: 1988-2012, IEEE J. Sel. Top. Appl., 9, 3144-3157, 2016.

Bi, H., Zhang, J., and Wang, Y.: Arctic Sea Ice Volume Changes in Terms of Age as Revealed From Satellite Observations, IEEE J. Sel. Top. Appl., 11, 1-15, 2018.

Cavalieri, D. J. and Parkinson, C. L.: Arctic sea ice variability and trends, 1979-2010, The Cryosphere, 6, 881-889, https://doi.org/10.5194/tc-6-881-2012, 2012.

Chen, X. and Tung, K. K.: Global surface warming enhanced by weak Atlantic overturning circulation, Nature, 559, 387-391, 2018.

Cho, K., Sasaki, N., Shimoda, H., Sakata, T., and Nishio, F.: Evaluation and improvement of SSM/I sea ice concentration algorithms for the Sea of Okhotsk, Journal of the Remote Sensing Society of Japan, 16, 47-58, 1996.

Comiso, J. C.: Arctic warming signals from satellite observations, Weather, 61, 70-76, 2010.

Comiso, J. C.: Large Decadal Decline of the Arctic Multiyear Ice Cover, J. Climate, 25, 1176-1193, 2011.

Comiso, J. C.: Bootstrap Sea Ice Concentrations from Nimbus-7 SMMR and DMSP SSM/I-SSMIS, Version 3. Boulder, Colorado USA. NASA National Snow and Ice Data Center Distributed Active Archive Center, https://doi.org/10.5067/7Q8HCCWS4I0R, 2017.

Comiso, J. C., Meier, W. N., and Gersten, R.: Variability and trends in the Arctic Sea ice cover: Results from different techniques, J. Geophys. Res., 122, 6883-6900, 2017.

Graham, R. M., Cohen, L., Petty, A. A., Boisvert, L. N., Rinke, A., Hudson, S. R., Nicolaus, M., and Granskog, M. A.: Increasing frequency and duration of Arctic winter warming events, Geophys. Res. Lett., 44, 6974-6983, 2017.

Hansen, E., Gerland, S., Granskog, M. A., Pavlova, O., Renner, A. H. H., Haapala, J., Løyning, T. B., and Tschudi, M.: Thinning of Arctic sea ice observed in Fram Strait: 1990-2011, J. Geophys. Res.-Oceans, 118, 5202-5221, 2013.

Hurrell, J. W.: Decadal trends in the north atlantic oscillation: regional temperatures and precipitation, Science, 269, 676-679, 1995.

Hurrell, J. W.: Decadal trends in the North Atlantic Oscillation, available at: http://www.cpc.ncep.noaa.gov/products/ precip/CWlink/pna/nao_index.html, last access: 4 March 2019.
Jia, W., Watanabe, E., Ikeda, M., Mizobata, K., Walsh, J. E., Bai, X., Wu, B., and Zhang, J.: Is the Dipole Anomaly a major driver to record lows in Arctic summer sea ice extent?, Geophys. Res. Lett., 36, 277-291, 2009.

Jung, T. and Hilmer, M.: The Link between the North Atlantic Oscillation and Arctic Sea Ice Export through Fram Strait, J. Climate, 14, 3932-3943, 2001.

Kalnay, E.: The NCEP/NCAR 40-year reanalysis project, available at: https://www.esrl.noaa.gov/psd/cgi-bin/db_search/ DBListFiles.pl?did $=195 \&$ tid $=72450 \&$ vid $=676$, last access: 4 March 2019a.

Kalnay, E.: The NCEP/NCAR 40-year reanalysis project, available at: https://www.esrl.noaa.gov/psd/cgi-bin/db_search/ DBListFiles.pl?did $=195 \&$ tid $=72451 \&$ vid $=3083$, last access: 4 March 2019b.

Kalnay, E.: The NCEP/NCAR 40-year reanalysis project, available at: https://www.esrl.noaa.gov/psd/cgi-bin/db_search/ DBListFiles.pl did=195\&tid=73261\&vid=1848, last access: 4 March 2019c.

Kalnay, E., Kanamitsu, M., Kistler, R., Collins, W., Deaven, D., Gandin, L., Iredell, M., Saha, S., White, G., and Woollen, J.: The NCEP/NCAR 40-Year Reanalysis Project, B. Am. Meteorol. Soc., 77, 437-472, 1996.

Kawaguchi, Y., Kikuchi, T., and Inoue, R.: Vertical heat transfer based on direct microstructure measurements in the ice-free Pacific-side Arctic Ocean: the role and impact of the Pacific water intrusion, J. Oceanogr., 70, 343-353, 2014.

Kay, J. E. and Gettelman, A.: Cloud influence on and response to seasonal Arctic sea ice loss, J. Geophys. Res.-Atmos., 114, D18204, https://doi.org/10.1029/2009JD011773, 2009.

Koyama, T., Stroeve, J., Cassano, J., and Crawford, A.: Sea Ice Loss and Arctic Cyclone Activity from 1979 to 2014, J. Climate, 30, 4735-4754, 2017.

Kwok, R.: Recent changes in Arctic Ocean sea ice motion associated with the North Atlantic Oscillation, Geophys. Res. Lett., 27, 775-778, 2000.

Kwok, R.: Near zero replenishment of the Arctic multiyear sea ice cover at the end of 2005 summer, Geophys. Res. Lett., 34, 306316, 2007.

Kwok, R.: Summer sea ice motion from the $18 \mathrm{GHz}$ channel of AMSR-E and the exchange of sea ice between the Pacific and Atlantic Sectors, Geophys. Res. Lett., 35, 144-151, 2008a.

Kwok, R.: Outflow of Arctic ocean sea ice into the Greenland and Barents Seas: 1979-2007, J. Climate, 22, 2438-2457, 2008b.

Kwok, R. and Cunningham, G. F.: Deformation of the Arctic Ocean ice cover after the 2007 record minimum in summer ice extent, Cold Reg. Sci. Technol., 76-77, 17-23, 2012.

Kwok, R. and Rothrock, D. A.: Decline in Arctic sea ice thickness from submarine and ICESat records: 1958-2008, Geophys. Res. Lett., 36, 1958-2008, 2009.

Kwok, R., Cunningham, G. F., and Yueh, S.: Area balance of the Arctic Ocean perennial ice zone: October 1996 to April 1997, J. Geophys. Res., 104, 25747-25759, 1999.

Kwok, R., Spreen, G., and Pang, S.: Arctic sea ice circulation and drift speed: Decadal trends and ocean currents, J. Geophys. Res.Oceans, 118, 2408-2425, 2013.

Lee, H. J., Kwon, M. O., and Yeh, S. W.: Impact of poleward moisture transport from the North Pacific on the acceleration of sea ice loss in the Arctic since 2002, J. Climate, 30, 6757-6769, 2017. 
Lindsay, R. W., Zhang, J., Schweiger, A., Steele, M., and Stern, H.: Arctic Sea Ice Retreat in 2007 Follows Thinning Trend, J. Climate, 22, 165-176, 2009.

Liu, Y., Key, J. R., and Wang, X.: The Influence of Changes in Cloud Cover on Recent Surface Temperature Trends in the Arctic, J. Climate, 21, 705-715, 2008.

Lynch, A. H., Serreze, M. C., Cassano, E. N., Crawford, A. D., and Stroeve, J.: Linkages between Arctic summer circulation regimes and regional sea ice anomalies: Arctic Summer Circulation and Sea Ice, J. Geophys. Res., 121, 7868-7880, 2016.

Maslanik, J., Stroeve, J., Fowler, C., and Emery, W.: Distribution and trends in Arctic sea ice age through spring 2011, Geophys. Res. Lett., 38, 392-392, 2011.

Meier, W. N.: Comparison of passive microwave ice concentration algorithm retrievals with AVHRR imagery in arctic peripheral seas, IEEE T. Geosci. Remote, 43, 1324-1337, 2005.

Nakamura, T., Yamazaki, K., Iwamoto, K., Honda, M., Miyoshi, Y., Ogawa, Y., and Ukita, J.: A negative phase shift of the winter AO/NAO due to the recent Arctic sea-ice reduction in late autumn, J. Geophys. Res.-Atmos., 120, 3209-3227, 2015.

Niederdrenk, A. L. and Notz, D.: Arctic sea ice in a $1.5^{\circ} \mathrm{C}$ warmer world, Geophys. Res. Lett., 45, 1963-1971, 2018.

Notz, D. and Stroeve, J.: Observed Arctic sea-ice loss directly follows anthropogenic $\mathrm{CO}_{2}$ emission, Science, 354, 747-750, 2016.

Ogi, M., Rysgaard, S., and Barber, D. G.: Importance of combined winter and summer Arctic Oscillation (AO) on September sea ice extent, Environ. Res. Lett., 11, 034019, https://doi.org/10.1088/1748-9326/11/3/034019, 2016.

Overland, J. E. and Wang, M.: Large-scale atmospheric circulation changes are associated with the recent loss of Arctic sea ice, Tellus A, 62, 1-9, 2010.

Overland, J. E., Wang, M., and Salo, S.: The recent Arctic warm period, Tellus A, 60, 589-597, 2010.

Parkinson, C.: Recent trend reversals in arctic sea ice extents: possible connections to the north Atlantic oscillation, Polar Geography, 31, 3-14, 2008.

Parkinson, C. L. and Comiso, J. C.: On the 2012 record low Arctic sea ice cover: Combined impact of preconditioning and an $\mathrm{Au}-$ gust storm, Geophys. Res. Lett., 40, 1356-1361, 2013.

Perovich, D. K., Light, B., Eicken, H., Jones, K. F., Runciman, K., and Nghiem, S. V.: Increasing solar heating of the Arctic Ocean and adjacent seas, 1979-2005: Attribution and role in the ice-albedo feedback, Geophys. Res. Lett., 34, L19505, https://doi.org/10.1029/2007GL031480, 2007.

Perovich, D. K., Richter-Menge, J. A., Jones, K. F., and Light, B.: Sunlight, water, and ice: Extreme Arctic sea ice melt during the summer of 2007, Geophys. Res. Lett., 35, 194-198, 2008.

Polyakov, I. V., Timokhov, L. A., Alexeev, V. A., Bacon, S., Dmitrenko, I. A., Fortier, L., Frolov, I. E., Gascard, J. C., Hansen, E., and Ivanov, V. V.: Arctic Ocean Warming Contributes to Reduced Polar Ice Cap, J. Phys. Oceanogr., 40, 2743-2756, 2010.

Rampal, P., Weiss, J., and Marsan, D.: Positive trend in the mean speed and deformation rate of Arctic sea ice, 1979-2007, J. Geophys. Res.-Oceans, 114, C05013, https://doi.org/10.1029/2008JC005066, 2009.

Rigor, I. G., Wallace, J. M., and Colony, R. L.: Response of Sea Ice to the Arctic Oscillation, J. Climate, 15, 2648-2663, 2002.
Schweiger, A. J., Lindsay, R. W., Vavrus, S., and Francis, J. A.: Relationships between Arctic Sea Ice and Clouds during Autumn, J. Climate, 21, 4799-4810, 2008.

Screen, J. A. and Francis, J. A.: Contribution of sea-ice loss to Arctic amplification is regulated by Pacific Ocean decadal variability, Nat. Clim. Change, 6, 856-860, 2016.

Screen, J. A. and Simmonds, I.: The central role of diminishing sea ice in recent Arctic temperature amplification, Nature, 464, 1334-1337, 2010.

Serreze, M. C., Maslanik, J. A., Scambos, T. A., Fetterer, F., Stroeve, J., Knowles, K., Fowler, C., Drobot, S., Barry, R. G., and Haran, T. M.: A record minimum arctic sea ice extent and area in 2002, Geophys. Res. Lett., 30, 365-389, 2003.

Shimada, K., Kamoshida, T., Itoh, M., Nishino, S., Carmack, E., Mclaughlin, F., Zimmermann, S., and Proshutinsky, A.: Pacific Ocean inflow: Influence on catastrophic reduction of sea ice cover in the Arctic Ocean, Geophys. Res. Lett., 33, 153-172, 2006.

Smedsrud, L. H., Halvorsen, M. H., Stroeve, J. C., Zhang, R., and Kloster, K.: Fram Strait sea ice export variability and September Arctic sea ice extent over the last 80 years, The Cryosphere, 11, 65-79, https://doi.org/10.5194/tc-11-65-2017, 2017.

Spreen, G., Kern, S., Stammer, D., and Hansen, E.: Fram Strait sea ice volume export estimated between 2003 and 2008 from satellite data, Geophys. Res. Lett., 36, L19502, https://doi.org/10.1029/2009GL039591, 2009.

Spreen, G., Kwok, R., and Menemenlis, D.: Trends in Arctic sea ice drift and role of wind forcing: 1992-2009, Geophys. Res. Lett., 38, L19501, https://doi.org/10.1029/2011GL048970, 2011.

Stroeve, J., Serreze, M., Drobot, S., Gearheard, S., Holland, M., Maslanik, J., Meier, W., and Scambos, T.: Arctic Sea Ice Extent Plummets in 2007, Eos Transactions American Geophysical Union, 89, 13-14, 2013.

Stroeve, J., Frei, A., Mccreight, J., and Ghatak, D.: Arctic sea-ice variability revisited, Ann. Glaciol., 48, 71-81, 2017.

Stroeve, J. C., Maslanik, J., Serreze, M. C., Rigor, I., Meier, W., and Fowler, C.: Sea ice response to an extreme negative phase of the Arctic Oscillation during winter 2009/2010, Geophys. Res. Lett., 38, 79-89, 2011.

Stroeve, J. C., Markus, T., Boisvert, L., Miller, J., and Barrett, A.: Changes in Arctic melt season and implications for sea ice loss, Geophys. Res. Lett., 41, 1216-1225, 2014.

Sumata, H., Lavergne, T., Girard-Ardhuin, F., Kimura, N., Tschudi, M. A., Kauker, F., Karcher, M., and Gerdes, R.: An intercomparison of Arctic ice drift products to deduce uncertainty estimates, J. Geophys. Res.-Oceans, 119, 4887-4921, 2015.

Szanyi, S., Lukovich, J. V., Barber, D. G., and Haller, G.: Persistent artifacts in the NSIDC ice motion dataset and their implications for analysis: Persistent Artifacts In Nsidc Ice Drift, Geophys. Res. Lett., 43, 10800-10807, 2016.

Thompson, D. W. J. and Wallace, J. M.: The Arctic Oscillation Signature in the Wintertime Geopotential Height and Temperature Fields, Geophys. Res. Lett., 25, 1297-1300, 1998.

Thompson, D. W. J. and Wallace, J. M.: Annular modes in the extratropical circulation, available at: http://www.cpc.ncep. noaa.gov/products/precip/CWlink/daily_ao_index/ao.shtml, last access: 4 March 2019.

Tjernström, M., Shupe, M. D., Brooks, I. M., Persson, P. O. G., Prytherch, J., Salisbury, D. J., Sedlar, J., Achtert, P., Brooks, B. J., 
and Johnston, P. E.: Warm-air advection, air mass transformation and fog causes rapid ice melt, Geophys. Res. Lett., 42, 55945602, 2015.

Tschudi, M., Stroeve, J., and Stewart, J.: Relating the Age of Arctic Sea Ice to its Thickness, as Measured during NASA's ICESat and IceBridge Campaigns, Remote Sensing, 8, 1-13, 2016.

Tschudi, M., Meier, W. N., Stewart, J. S., Fowler, C., and Maslanik, J.: Polar Pathfinder Daily $25 \mathrm{~km}$ EASE-Grid Sea Ice Motion Vectors, Version 3, Boulder, Colorado USA. NASA National Snow and Ice Data Center Distributed Active Archive Center, https://doi.org/10.5067/INAWUWO7QH7B [2018-07-31], 2019a.

Tschudi, M. A., Meier, W. N., and Stewart, J. S.: An enhancement to sea ice motion and age products, The Cryosphere Discuss. https://doi.org/10.5194/tc-2019-40, 2019 b.

Tverberg, V., Nøst, O. A., Lydersen, C., and Kovacs, K. M.: Winter sea ice melting in the Atlantic Water subduction area, Svalbard Norway, J. Geophys. Res.-Oceans, 119, 5945-5967, 2014.

Wang, J., Ikeda, M., Zhang, S., and Gerdes, R.: Linking the northern hemisphere sea-ice reduction trend and the quasi-decadal arctic sea-ice oscillation, Clim. Dynam., 24, 115-130, 2005.
Woods, C., Caballero, R., and Svensson, G.: Large-scale circulation associated with moisture intrusions into the Arctic during winter, Geophys. Res. Lett., 40, 4717-4721, 2013.

Wu, B., Wang, J., and Walsh, J. E.: Dipole Anomaly in the Winter Arctic Atmosphere and Its Association with Sea Ice Motion, J. Climate, 19, 210-225, 2005.

Zhang, J., Steele, M., and Schweiger, A.: Arctic sea ice response to atmospheric forcings with varying levels of anthropogenic warming and climate variability, Geophys. Res. Lett., 37, 1400-1416, 2010.

Zhang, J., Lindsay, R., Schweiger, A., and Rigor, I.: Recent changes in the dynamic properties of declining Arctic sea ice: A model study, Geophys. Res. Lett., 39, L20503, https://doi.org/10.1029/2012GL053545, 2012.

Zhang, X., Sorteberg, A., Zhang, J., Gerdes, R., and Comiso, J. C.: Recent radical shifts of atmospheric circulations and rapid changes in Arctic climate system, Geophys. Res. Lett., 35, L22701, https://doi.org/10.1029/2008GL035607, 2008.

Zhang, X., He, J., Zhang, J., Polyakov, I., Gerdes, R., Inoue, J., and $\mathrm{Wu}, \mathrm{P}$.: Enhanced poleward moisture transport and amplified northern high-latitude wetting trend, Nat. Clim. Change, 3, 47-51, 2013. 